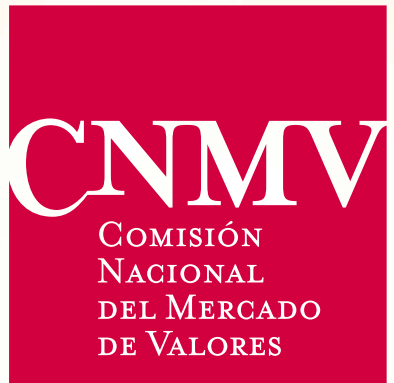

Measuring liquidity of Spanish debt

Ma Isabel Cambón Murcia José Luis Cano Coello Jesús González Redondo

Documentos de Trabajo

$N^{\circ} 66$ 



\section{Measuring liquidity of Spanish debt}

Ma Isabel Cambón Murcia, José Luis Cano Coello and Jesús González Redondo

Working paper

No. 66

xxxx 2017

* We thank Leticia Carpintero for providing a lot of information regarding previous studies on bond liquidity and fixed-income markets dynamics. 
The opinions in this Working Paper are the sole responsibility of the authors and they do not necessarily coincide with those of the CNMV.

The CNMV publishes this Working Paper Series to enhance research and contribute towards greater knowledge of the stock markets and their regulation.

The CNMV distributes its reports and publications via the internet at www.cnmv.es

(C) CNMV. The contents of this publication may be reproduced, subject to attribution.

Layout \& printing: Composiciones Rali, S.A. 


\section{Abstract}

Assessing liquidity in fixed-income markets is becoming very important in the current context of extremely low interest rates which, in general terms, is encouraging the acquisition of riskier and (potentially) less liquid assets. Although there is the perception that bond market liquidity could have worsened over the last years in international markets, none of the current studies has reached a clear conclusion. In this paper, we propose a liquidity synthetic indicator (LSI) on Spanish debt, applying the methodology that Broto and Lamas (2016) used for US markets. We compute six individual liquidity indicators that represent the elements that characterise a liquid market (tightness, resilience, depth and breadth). We use price and transaction-based indicators for government and corporate debt when data is available for the period 2005-2016. Our LSI shows several episodes of significant worsening in liquidity conditions, related to the Lehman Brothers' collapse and the European sovereign debt crisis. After a sizeable improvement of liquidity in 2013-2014, the liquidity indicator has deteriorated over the past months as a consequence of lower trading volumes. The current ultralow interest rate environment and more capital demanding regulations could partially explain these results.

Keywords: liquidity measures, synthetic indicator, Spanish fixed-income market.

JEL Classification: Go1,G10, G15 and C43. 



\section{Table of contents}

1. Introduction

2. Background and international evidence

3. Individual market liquidity indicators 21

\begin{tabular}{llr}
\hline $3.1 \quad$ Data & 21
\end{tabular}

\begin{tabular}{llr}
3.1 & Data & 21 \\
\hline
\end{tabular}

$\begin{array}{llr}3.2 & \text { Selection of individual liquidity indicators } & 23\end{array}$

\begin{tabular}{lll}
\hline $3.3 \quad$ Individual liquidity indicators for the Spanish fixed income markets & 25
\end{tabular}

$4 \quad$ The market liquidity synthetic indicator (LSI) 29

\begin{tabular}{llr}
\hline $4.1 \quad$ Methodology & 29
\end{tabular}

\begin{tabular}{lll}
\hline 4.2 Results & 31
\end{tabular}

\begin{tabular}{lll}
4.2 & Results & 31 \\
\hline
\end{tabular}

\begin{tabular}{lll}
\hline 4.2.1 Total market liquidity indicator & 31
\end{tabular}

4.2.2 Sectoral liquidity indicators (financial and non-financial) 33

$5 \quad$ Evaluation of the LSI $\quad 35$

5.1 The liquidity indicator and the financial stress indicator 35

5.2 Relationship between the liquidity indicator and liquidity performance of Spanish mutual fund

5.3 The LSI and and ESMA criteria for liquid assets 38

\begin{tabular}{lll}
\hline 5.4 & The liquidity approach under ESMA's work : a robustness analysis & 40
\end{tabular}



Index of Tables

\begin{tabular}{llr} 
TABLE 1 & Number of bonds with available data & 21 \\
\hline TABLE 2 & Number of transactions & 23 \\
\hline TABLE 3 & Individual liquidity indicators & 25 \\
\hline TABLE 4 & Principal component analysis & 31 \\
\hline
\end{tabular}

$\begin{array}{lll}\text { TABLE A.3 Individual liquidity indicators weights (total market) } & 51\end{array}$





\section{Index of Figures}

\begin{tabular}{llr} 
FIGURE 1 & Bloomberg liquidity assessment tool & 17 \\
\hline FIGURE 2 & 10-year public debt bid-ask spread (\%) & 18 \\
\hline FIGURE 3 & Trade sizes of corporate debt transactions (euros) & 18 \\
\hline FIGURE 4 & Issuance volume of Spanish debt (million euros) & 22 \\
\hline FIGURE 5 & Individual liquidity indicators & $26-27$ \\
\hline FIGURE 6 & The liquidity synthetic indicator (LSI) & 32 \\
\hline FIGURE 7 & The liquidity indicator: Spanish market versus Spanish issuers & 33 \\
\hline FIGURE 8 & The liquidity indicator by liquidity characteristic and sector & 34 \\
\hline FIGURE 9 & The liquidity indicator versus the market stress indicator & 36 \\
\hline FIGURE 10 & The liquidity indicator versus illiquid assets in investment funds' portfolio & 37 \\
\hline FIGURE 11 & Number of Spanish liquid bonds under ESMA criteria & 39 \\
\hline FIGURE 12 & Panel of liquidity indicators under ESMA's approach & 42 \\
\hline
\end{tabular}





\section{Introduction}

The concept of liquidity is very intuitive and apparently easy. It is related to the possibility of selling any kind of asset in a short period of time without making significant losses. But what is a short period of time? And what is a significant loss? These concepts may have very different interpretations. In the context of financial markets, giving accurate measures of liquidity for each of the existing assets is challenging; however we can rank the instruments considering general liquidity conditions. Therefore, we can say that cash is the most liquid asset and that equities are also, in general, very liquid. However, certain structured products and derivatives or, in general, products with low or without secondary market activity are very illiquid. Debt liquidity would be in an intermediate position: on one hand, these products may have a secondary market that allows trading (improvement in liquidity) but, on the other hand, these products are very heterogeneous and many of them are not traded for long periods of time.

Assessing liquidity in fixed-income markets is becoming increasingly important given the new regulation implemented in response to the global financial crisis and the current extremely low interest rates environment that is encouraging the acquisition of riskier and (potentially) less liquid assets. Although there is the perception that bond market liquidity could have worsened over the last years in international markets, none of the current studies ${ }^{1}$ have reached a clear conclusion. From the point of view of CNMV, assessing debt liquidity is relevant not only as part of the tasks related to financial stability but also because of its supervisory function.

In this paper, we propose a liquidity synthetic indicator (LSI) on Spanish debt, applying the methodology that Broto and Lamas (2016) used for US markets. We compute six individual liquidity indicators, based on prices and transactions, which represent different dimensions of liquidity (tightness, resilience, depth and breadth). Our LSI shows several episodes of significant worsening in liquidity conditions, related to the Lehman Brothers collapse and the European sovereign debt crisis. After a sizeable improvement of liquidity in 2013-2014, the LSI has deteriorated over the last months as a consequence of lower trading volumes.

The paper is structured as follows: section 2 summarizes previous international studies on bond liquidity. Section 3 provides the details of the data used and the selection of individual indicators. Section 4 explains the main points of the statistical design of the LSI and describes the results obtained. Section 5 presents an evaluation of the LSI: (i) LSI and the financial stress indicator are compared, (ii) LSI and

1 See IMF (2015) and PWC (2015). 
performance of liquidity of mutual funds portfolio are also tested and (iii) ESMA criteria in order to consider a bond as liquid (for transparency purposes) are applied to our sample data and results are compared with LSI's trend. Finally, section 6 lays out the main conclusions. 


\section{Background and international evidence}

Measuring liquidity in equity markets is easy, being bid-ask spreads commonly used. In general, bond markets are more illiquid in nature. There are a huge number of fixed-income securities that are not homogeneous and consequently, traditional measures of liquidity cannot be fully applied in this context. Moreover, a relatively high proportion of bonds are not traded every day. The existing international evidence trying to measure liquidity in bond markets has taken into account the particular characteristics of bond markets in comparison with other financial markets. In general, these studies have computed several liquidity indicators based on prices and volumes, capturing different aspects of liquidity.

According to Sarr and Lybek (2002) market liquidity is characterized by five elements: tightness, immediacy, depth, breadth and resilience. Tightness is related to transaction costs, immediacy is the characteristic of markets where trades are executed quickly. Depth is related to traded volume and number of orders and breadth is the element that allows trading with a modest impact in prices, even if the orders size is large. Finally, resilience points to the capacity of prices to move rapidly to new equilibrium levels. For that reason resilience can be related to market efficiency. The quantitative analysis has also been complemented with several qualitative analyses, mainly with the output of surveys. In general, research is trying to test if liquidity conditions in bond markets over the last quarters are worse than liquidity conditions just before the international crisis of 2008 .

In the European context, we find two interesting papers measuring liquidity in bond markets: ${ }^{2}$ the AMF (2015) and the FCA (2016). In the AMF (2015), a composite measure of liquidity is proposed for the French bond market. They use three liquidity indicators: the bid-ask spread indicator, the zero return indicator and a price impact indicator for government and corporate bonds and compute a single average in order to obtain the composite indicator. In the FCA (2016), the authors evaluate the liquidity in the British corporate bond market computing the following measures: the Amihud index, a measure of imputed roundtrip costs, a measure which estimates the magnitude of price reversals, the turnover ratio and the number of zero trading days. With these measures, they try to capture depth, breadth and

There are also several recent studies on bond market liquidity in Sweden. The Swedish Financial Supervisory Authority proposed a yield impact indicator that tries to capture price/yield shifts due to a trade. This measure has been constant over the recent past and no significant worsening in liquidity conditions has been observed. However the Authority is concerned about liquidity resilience when monetary stimulus disappears. The Swedish Central Bank has also studied this topic computing several quantitative measures (see Bonthron, Johansson and Mannent (2016)). They conclude that different measures provide different pictures and it is difficult to draw unequivocal conclusions. However, the general assessment is that liquidity has recently deteriorated somewhat although risks to financial stability have not increased. 
resilience. The results for France suggest that bond liquidity has improved since the beginning of 2012, although without returning to levels seen before the outbreak of the subprime crisis. In the UK, the authors conclude that although the inventory of dealers has declined over the last years, there is no evidence that liquidity outcomes have deteriorated in the market. However, they state that they can't predict liquidity performance under stressful times. In February 2017, the FCA has published new evidence on liquidity in UK corporate bond markets using standard measures of liquidity and also measures of dealers' ease on trading. They find that there has been a decline in liquidity from mid-2014 onwards, although the reduction appears to be moderate from a long-term perspective. ${ }^{3}$

ESMA has also published two articles investigating market liquidity referring to corporate and sovereign debt markets in the EU. The first study, ${ }^{4}$ based on EU corporate bond markets, takes into account that liquidity is a multidimensional concept and presents quantity-based and price-based metrics of market liquidity in order to provide a first attempt of a composite liquidity index. They find evidence of several episodes signalling deteriorating secondary market liquidity in the studied period: 2014-2016. The second study also proposed a synthetic indicator of market liquidity in the EU government bond markets, ${ }^{5}$ covering the period from 2006 to 2016 in domestic and EuroMTS platforms. They conclude that after a significant deterioration of liquidity in 2008 and 2012, sovereign bond market liquidity has improved over the last three years. The authors also highlight the heterogeneity between markets and platforms.

Information gathered from European market makers shows a decreasing trend in inventories in corporate bond markets and a more mixed trend for other asset classes where trading volumes have remained relatively constant. Median trade sizes have decreased across all asset classes signalling changes in market behaviour and potential liquidity contraction. Combining quantitative and qualitative data the general conclusion is that most measures show little or no decline in market liquidity over the last years, although alternative measures suggest a possible deterioration in the segment of corporate bonds.

Private providers of business and financial information have also identified the need of market participants to evaluate asset liquidity, developing several interesting tools. Bloomberg, for example, offers its Liquidity Assessment tool (LQA) that helps banks, broker dealers, hedge funds and other participants to understand the probability of selling a specific volume of securities at a specific price, along with the expected cost of liquidation, maximum volume and days to liquidate given a maximum market impact. Finally, the tool delivers a liquidity score designed to indicate security-level liquidity with respect to market impact (see figure 1). The final score is a percentile from 1 to 100 . Bonds with a score close to 100 are the most liquid of the universe, while bonds with a score close to 1 are the least liquid in the universe.

3 https://www.fca.org.uk/publications/research/new-evidence-liquidity-uk-corporate-bond-markets.

4 ESMA Report on Trends, Risks and Vulnerabilities № 2, 2016.

5 ESMA Report on Trends, Risks and Vulnerabilities № 1, 2017. 
More recently, Broto and Lamas (2016) presented a new synthetic indicator that measured market liquidity in US fixed-income markets, proposing seven individual liquidity indicators for corporate and government debt. They compute a synthetic indicator transforming the indices with the methodology proposed by Holló et al. (2012) for the CISS and the Principal Component Analysis. Their conclusions are similar to other empirical papers: liquidity in debt markets has improved with respect to the financial crisis but it has not reached pre-crisis levels. One of the most interesting contributions of this paper is on the ability to explain the origin of the liquidity performance. In fact, the deterioration of liquidity over the last quarters, they observe, can be associated with public debt and with market depth.

\section{Bloomberg liquidity assessment tool}

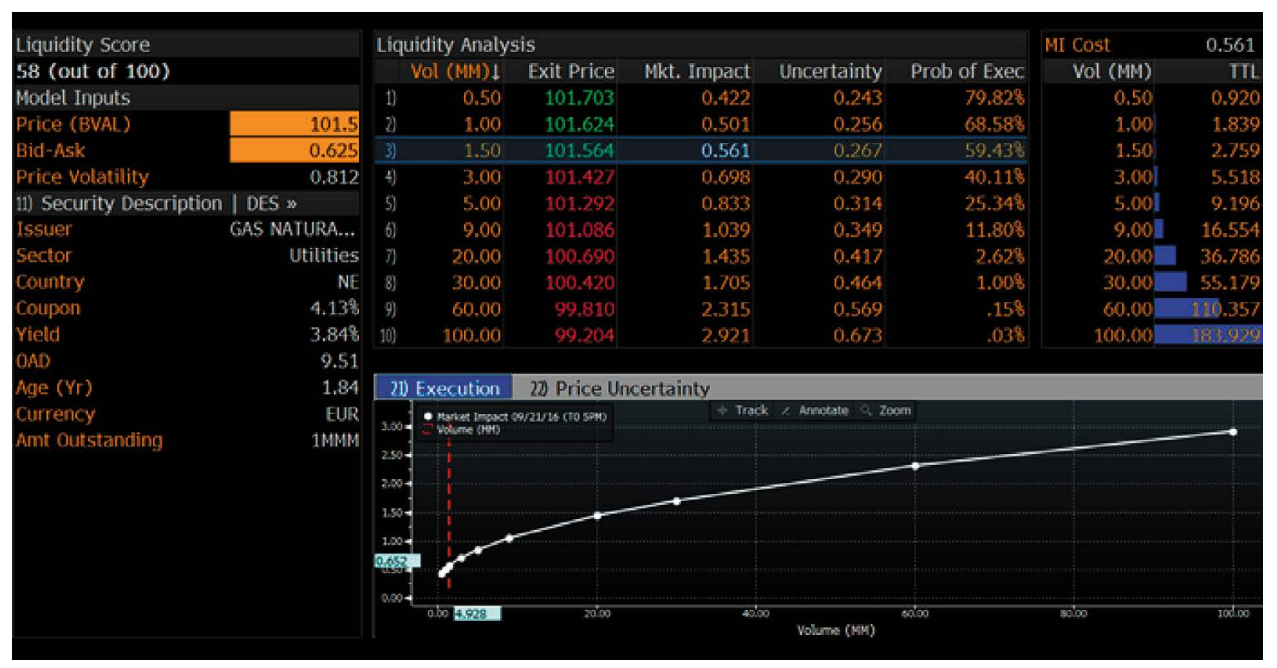

Source: Bloomberg.

Evidence related to the liquidity conditions in the Spanish markets is scarce. Ten year public bond bid-ask spread is usually used to evaluate liquidity in these markets (see figure 2) but this measure does not show a complete picture of bond liquidity conditions for several reasons: (i) it only refers to public debt liquidity that, in general, performs better than corporate bond liquidity, (ii) it only refers to one characteristic of liquidity: tightness or transaction costs but does not take into account other characteristics such as depth, breadth or resilience, (iii) it's based only on prices, volumes are not included. 


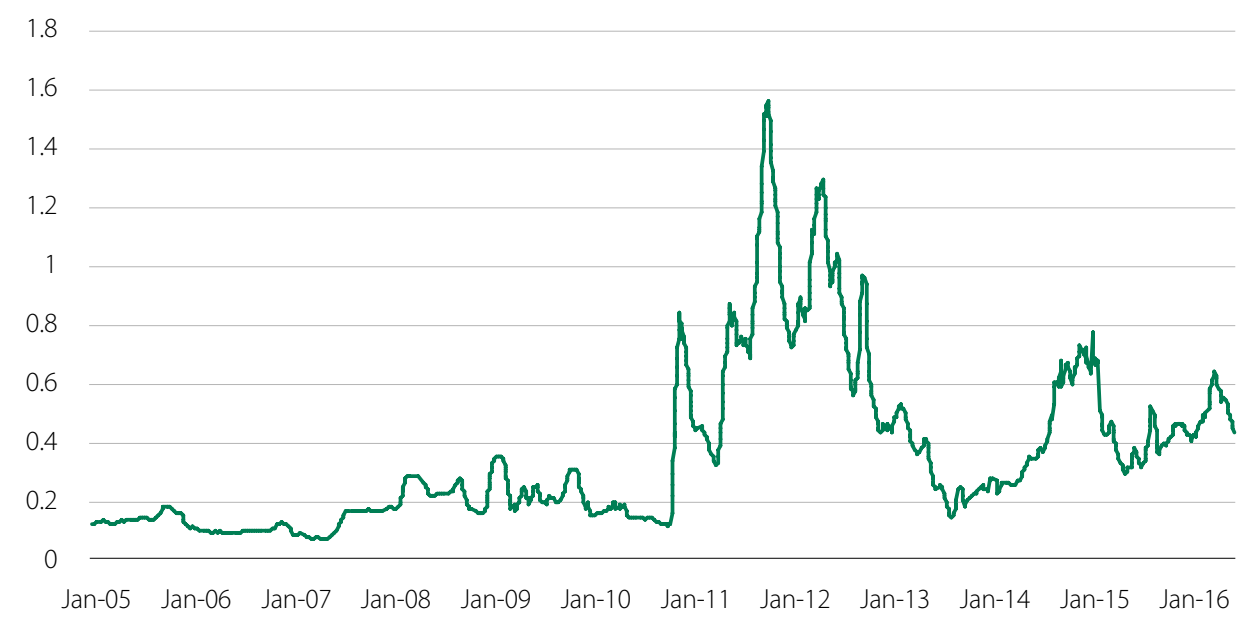

Source: Bloomberg

There is relevant information that we can obtain from individual transactions of corporate bonds. For example, we can calculate trade size performance over time and try to figure out if changes in the size of the transaction can be related to liquidity issues. According to the information provided in figure 3, a median trade sizes trend has been irregular but, in general, they have increased both for financial and non-financial corporations during most of the sample period suggesting an improvement in liquidity conditions. In the case of financial companies, where trade sizes reached a maximum during the first quarter of 2012 and at the end of 2014, we observe a reduction in trade sizes since the beginning of 2015 although the numbers are still above pre-crisis levels. Average trade sizes of non-financial companies have been more stable during the last part of the sample.

Trade sizes of corporate debt transactions (euros)

FIGURE 3

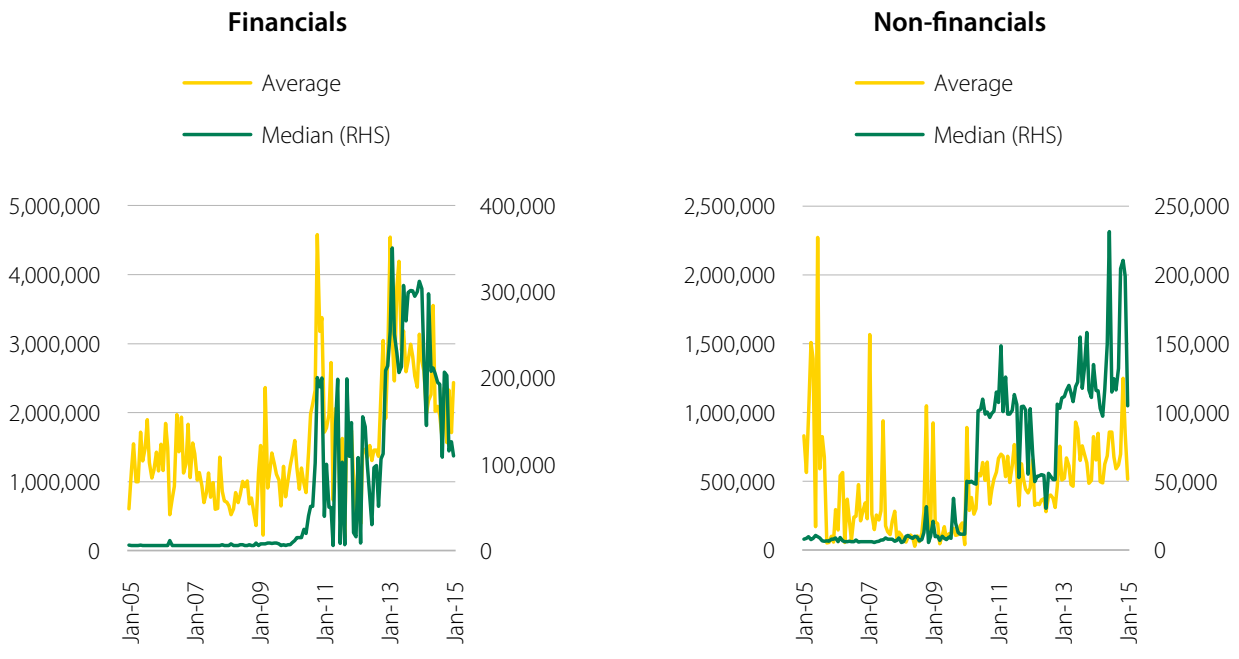

Source: CNMV. Monthly calculations.

In order to reach a clearer conclusion about liquidity conditions in Spanish fixed-income markets, we should analyse different characteristics of liquidity and combine 
prices and data on transactions. For that reason, we propose in this paper a Spanish market liquidity synthetic indicator (LSI) between 2005 and 2016 applying Broto and Lamas's (2016) methodology. We compute some of the individual liquidity indicators they used like bid-ask spreads, turnover or the Amihud ratio and we add another one related to market depth, which is the proportion of bonds that are traded (on a daily basis). In total we compute six individual liquidity indicators for government and corporate debt when data is available.

Additionally, we provide a threefold evaluation section of the liquidity indicator. Firstly, we compare the performance of this indicator with CNMV's Financial Markets Stress Index (FMSI), used in our regular risk analysis. Secondly, we test if there is any relationship between the liquidity indicator and the regular analysis of liquidity conditions of the mutual funds private debt portfolio that CNMV has developed since the beginning of the crisis. Thirdly, we compare our LSI with the results of applying ESMA's criteria for liquid assets to our data base in order to check potential similarities or differences between them. In addition, we compare our methodology with the one that is currently being discussed in an ESMA working group. The purpose of this group, with members of most of EU's jurisdictions, is the analysis of bond liquidity at a European level during 2012-2016. 



\section{Individual market liquidity indicators}

\subsection{Data}

In order to compute our liquidity synthetic indicator we use price-based metrics and quantity-based metrics. Our sources of data are different depending on the metrics tested. We use Bloomberg to obtain prices of Spanish debt securities whereas we use internal data bases in order to obtain transactions data. In particular, we use data from AIAF, which is the main Spanish fixed-income market, and data from TREM (Transaction Reporting Exchange Mechanism) in order to incorporate OTC and foreign regulated market transactions.

Our price-based metrics include data on private and public bonds where the country of risk is Spain. ${ }^{6}$ We require these assets to be active at some moment of the sample period considered in this study (2005-2016). Table 1 shows the number of bonds with available information regarding bid, ask and close prices. We have information of bid-ask spreads for 494 government bonds and 865 private bonds and information of closing prices for 1,096 government bonds and 1,990 private bonds.

Number of bonds with available data

TABLE 1

\begin{tabular}{lrrr}
\cline { 2 - 4 } Indicator & Government & Financial & Non-Financial \\
\hline Bid-ask spread & 494 & 614 & 251 \\
\hline Last Price & 1,096 & 1,484 & 506 \\
\hline
\end{tabular}

Source: Bloomberg.

On transactions data, we have AIAF information for the whole period and TREM information since $2011 .^{7}$ We use data on 7,678 private debt issues that were active at any moment of our reference period (2005-2016), 6,950 issued by financial institutions and 728 issued by non-financial corporations. These data include 1,887 issues listed abroad, but issued by Spanish issuers. The data show that on average only $10.5 \%$ of gross issuance was done by non-financial corporations, although this ratio has increased significantly in recent years up to values over $15 \%(17 \%$ in 2016). Moreover, non financial corporations usually issue debt in foreign markets with an average of $90 \%$ of total gross issuance. We consider the following

6 The field "country of risk" in Bloomberg provides the ISO country code of the issuer's country of risk. Methodology consists of four factors listed in order of importance: management location, country of primary listing, country of revenue and reporting currency of the issuer.

7 TREM data for years before 2011 is not available or its quality is not good enough. 
asset classes: bonds (including public sector guaranteed bonds), securitisations (MBS and ABS) and covered bonds. ${ }^{8}$ Figure 4 shows the evolution of gross issuance for different asset classes and issuers.

Spanish debt: Issuance volume (million euros)

Financials

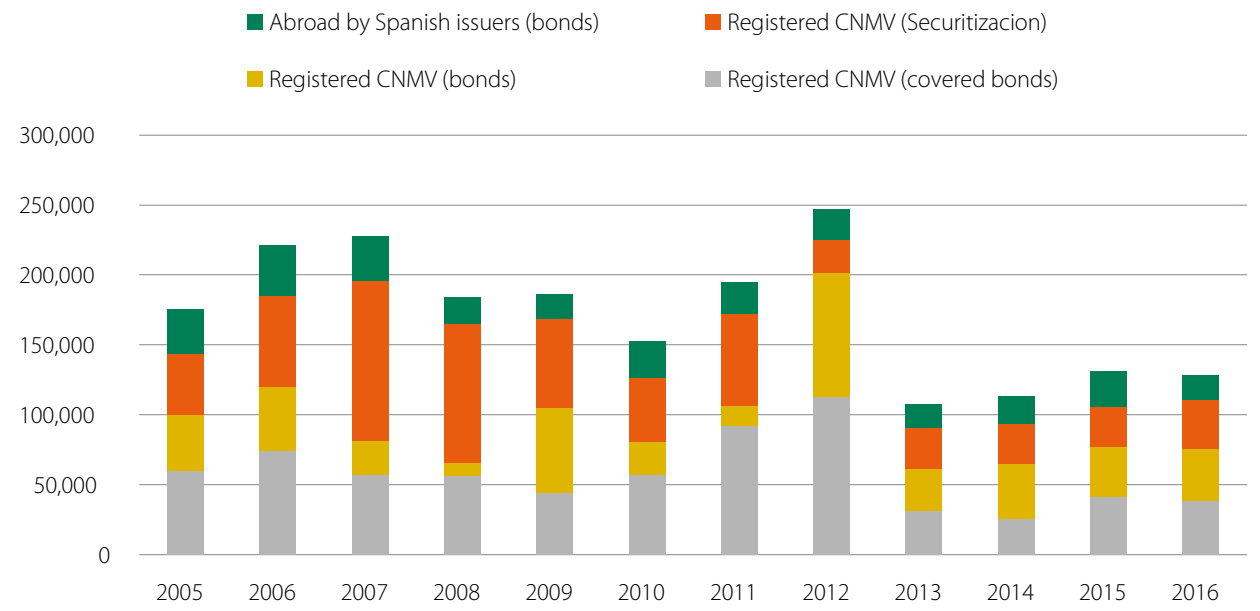

Non-financials

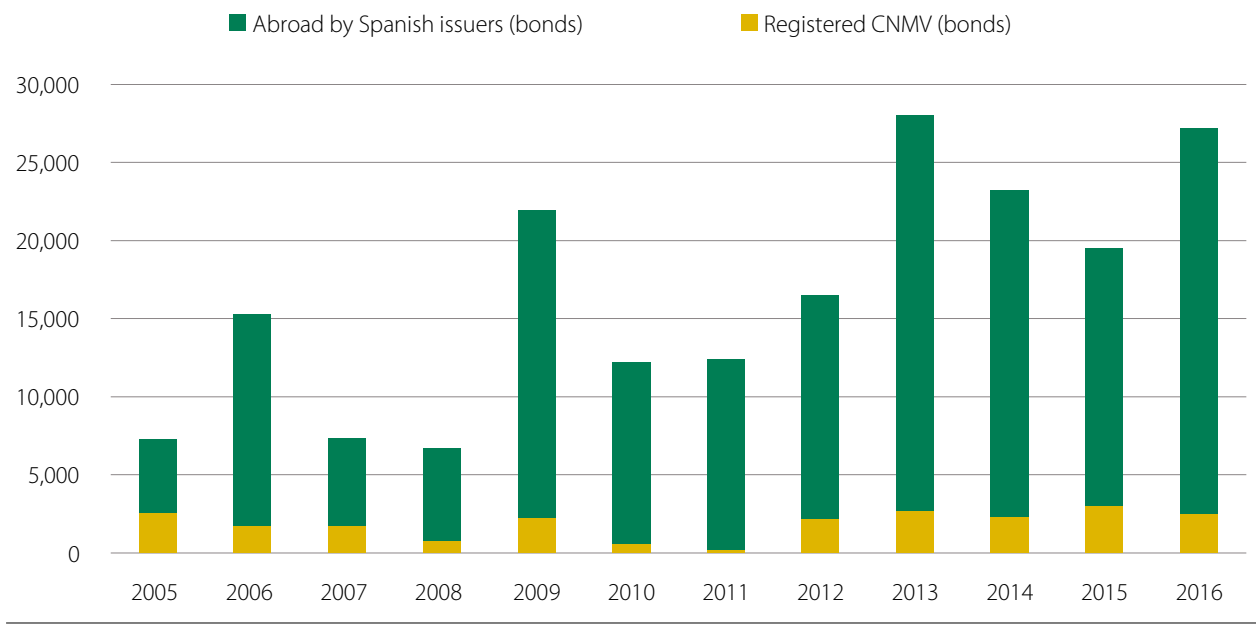

Source: CNMV and Bloomberg.

Regarding transactions, we only consider outright transactions. Repos and sell-buybacks/buy-sellback operations have not been included because they do not represent liquidity conditions in the market in the way we want to test. These transactions have been frequently linked to two operations during the last years: i) the use of instruments listed on AIAF as collateral in the financing operations of the ECB and ii) the cash operations conducted in the market by the General Secretariat of the Treasury and Financial Policy. After all these considerations, we have information

8 TREM transactions are related to Spanish debt. We are not able to distinguish different types of assets. 
on almost 2,830,000 transactions coming from AIAF and 766,000 coming from TREM (see table 2 ). ${ }^{9}$

Number of transactions

TABLE 2

\begin{tabular}{|c|c|c|c|c|c|}
\hline AIAF & & & Financial & Non-Financial & Total \\
\hline Type & Bonds & Securitisation & Covered & Bonds & \\
\hline of asset & (and debentures) & & bonds & and debentures) & \\
\hline 2005 & 145,839 & 3,465 & 9,035 & 8,445 & 166,784 \\
\hline 2006 & 144,266 & 3,951 & 40,843 & 10,085 & 199,145 \\
\hline 2007 & 146,301 & 5,570 & 62,855 & 10,249 & 224,975 \\
\hline 2008 & 181,459 & 11,227 & 122,130 & 9,033 & 323,849 \\
\hline 2009 & 199,748 & 5,731 & 195,230 & 11,376 & 412,085 \\
\hline 2010 & 165,541 & 3,671 & 31,727 & 10,526 & 211,465 \\
\hline 2011 & 146,577 & 9,293 & 48,727 & 7,735 & 212,332 \\
\hline 2012 & 150,162 & 9,225 & 190,681 & 10,869 & 360,937 \\
\hline 2013 & 304,655 & 11,811 & 38,351 & 41,688 & 396,505 \\
\hline 2014 & 97,052 & 8,604 & 32,586 & 31,732 & 169,974 \\
\hline 2015 & 40,012 & 6,161 & 21,136 & 14,474 & 81,783 \\
\hline 2016 & 36,896 & 5,542 & 11,842 & 15,585 & 69,865 \\
\hline $\begin{array}{l}\text { Foreign markets } \\
\text { and OTC }\end{array}$ & & Financial & & Non-Financial & Total \\
\hline 2011 & & 40,699 & & 23,175 & 63,874 \\
\hline 2012 & & 84,440 & & 67,778 & 152,218 \\
\hline 2013 & & 123,825 & & 74,806 & 198,631 \\
\hline 2014 & & 106,286 & & 54,051 & 160,337 \\
\hline 2015 & & 64,347 & & 44,230 & 108,577 \\
\hline 2016 & & 48,166 & & 34,360 & 82,526 \\
\hline
\end{tabular}

Source: AIAF, Bloomberg and CNMV.

1 Data of issues traded in foreign markets and OTC where the country of risk of the issuer is Spain. The data is obtained through the Transaction Reporting Exchange Mechanism (TREM), that shares information with European regulators through the Transaction Reporting Exchange Mechanism (TREM), which allows regulators in the European Economic Area (EEA) to share information about transactions involving a financial instrument over which another regulator has and transactions reported by branches of foreign investment firms to their host regulator.

\subsection{Selection of individual liquidity indicators}

We have chosen six indicators representing several aspects of liquidity, although there is a lack of data to compute them for all the relevant sectors: government, financials and non-financials. In general, indicators based on prices can be estimated

9 TREM transactions dataset has been cleaned due to the possibility of misreporting. In particular, we have not considered: (i) transactions over 500 million euros, (ii) transactions under 1,000 euros, (iii) transactions with reported price lower than 30 or bigger than 150, (iv) transactions that imply turnovers of over 0.50 . In total, we have removed $5.5 \%$ of TREM transactions. 
for all the sectors and indicators based on volumes (transactions) are only available for corporate debt. In total, we can estimate 14 individual liquidity indicators. Our indicators try to capture different characteristics of liquidity: tightness, depth, breadth and resilience and are calculated on a weekly basis. A brief summary of these indicators and data sources can be found in table 3 .

The six liquidity indicators that we have computed for the Spanish fixed-income market are the following:

- $\quad$ Bid ask spread. It is the difference between the price quoted for an immediate sale (bid) and an immediate purchase (offer) of a security (divided by the average of both prices). The size of the bid-ask is one of the most commonly used measures of liquidity in financial markets and can be interpreted as a measure of the cost of executing a trade. In this sense, the spread is included in the analysis representing the tightness of the market or transaction costs. If the spread is low, liquidity conditions are better because buying and selling prices tend to be similar. We use Bloomberg bid-ask prices to perform this indicator.

- Volume. It is calculated as the amount of traded securities (in euros). Transaction data come from AIAF, the Spanish fixed-income market, and TREM and are available for private debt: financial and non-financials. Volume is one of the indicators that represent market depth, which is the ability of the market to sustain relatively large market orders without impacting the price of the security. Higher volume tradings are usually related to liquid markets.

- Turnover rate. It is defined as the trading volume over the size of the issuance volume. This rate indicates the proportion of the market that is traded during a period and is also a good measure of market depth. A high turnover rate indicates that a great proportion of the issuance volume is traded and consequently a high level of liquidity.

- Percentage of traded bonds. It is calculated as the proportion of bonds that is traded every period divided by the total number of active bonds in that period. It is very well known that in fixed-income markets there are a large proportion of instruments that are not traded during long periods of time. Trading is usually concentrated in one or a few debt issues by an issuer, being these issues very liquid and the rest much more illiquid (usually the benchmarks). This indicator is the third representor of market depth.

- Amihud ratio. The Amihud ratio tries to measure the effect on return of a given trading volume. ${ }^{10}$ In our context, this ratio is calculated as the absolute

10 The Amihud measure is defined as: Amihud $_{i, t}=\frac{1}{N_{i, t}} \frac{\sum_{j=1}^{N_{i, t}}\left|R_{i, t, d}\right|}{V_{i, t, d}}$ where $\mathrm{V}_{\mathrm{i}, \mathrm{t}, \mathrm{d}}$. is the value traded of security $i$ on date $t, R_{i, t, d}$ is the return between the trade $i$ and the trade $i+1$ and $N_{i, t}$ is the total number of returns on day t. For more details, see Amihud (2002). Given that many debt instruments do not trade every day, we have chosen a simpler version of this measure, defined as the daily return divided by the total daily volume. 
(daily) return to (daily) volume. This indicator, commonly used for equity assets, is a measure of market breadth. A liquid market should be characterised by low Amihud ratios. The intuition behind this indicator is related to the ability of the market to absorb high trading volumes (or large size orders) without significantly impacting on prices.

- Market Efficiency Coefficient (MEC). We compute the Market Efficiency Coefficient proposed by Hasbrouck and Schwartz (Sarr and Lybek 2002). The indicator is calculated as the variance of returns in a long period of time (in this case one week) divided by the variance of returns in a short period of time (in this case a day). This indicator is a proxy of market resilience and the idea is that in a resilient market short and long term volatilities tend to be similar because prices tend to move faster to new equilibrium prices. For that reason, higher values of this indicator (long term variance exceed significantly short term variance) are associated to less resilient markets.

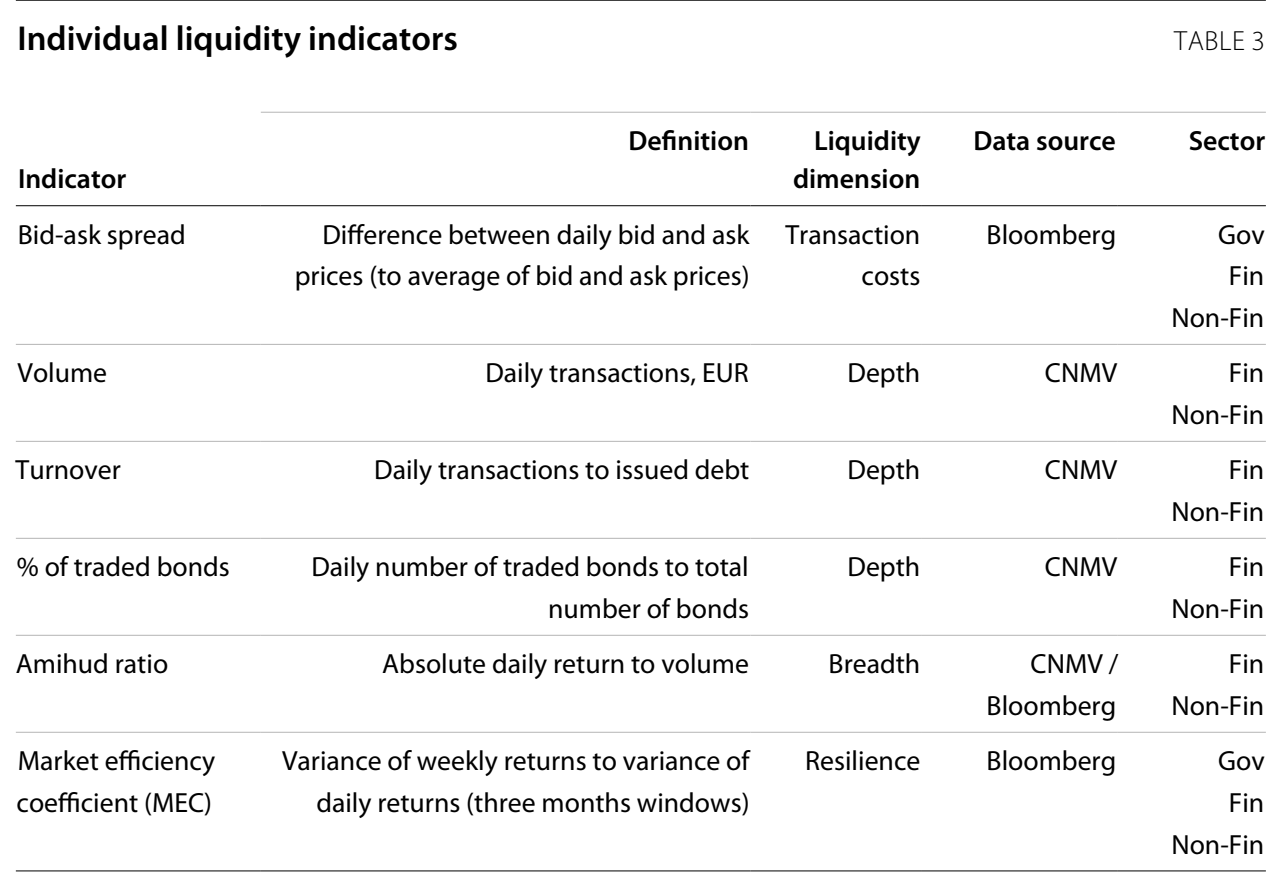

Source: CNMV.

\subsection{Individual liquidity indicators for the Spanish fixed income markets}

Figure 5 reports all the individual liquidity indicators, which describe different patterns of liquidity conditions across sectors and also across indicators. In general, price indicators (bid ask spreads and MEC) present negative correlation with transactions based indicators (volume, turnover and percentage of traded bonds). Bid ask spreads started to increase in 2010 when the first episode of uncertainty of the Greek economy took place in the context of the European debt crisis. Maximum levels for government and financial debt were reached in the second half of 2012, just after the Spanish government asked for financial assistance for the banking sector. During 2013 and 2014 bid ask levels reduced significantly, although more recently they have showed a slight increase across sectors. 
Bid-ask pread (per unit)
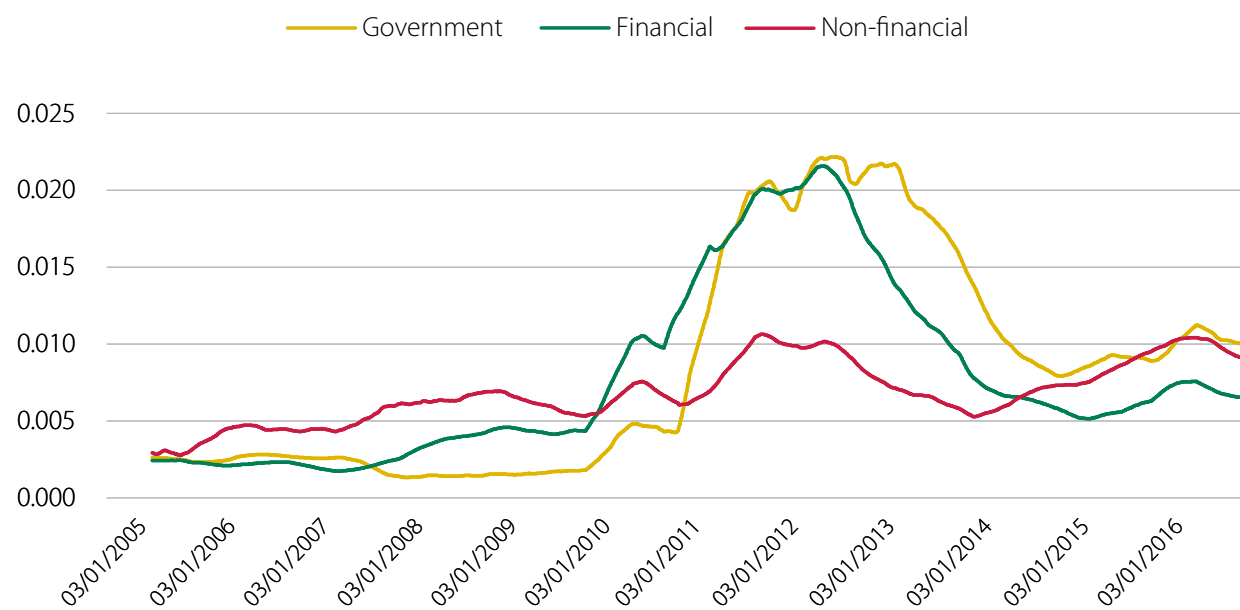

- Financial — Non-financial (RHS)

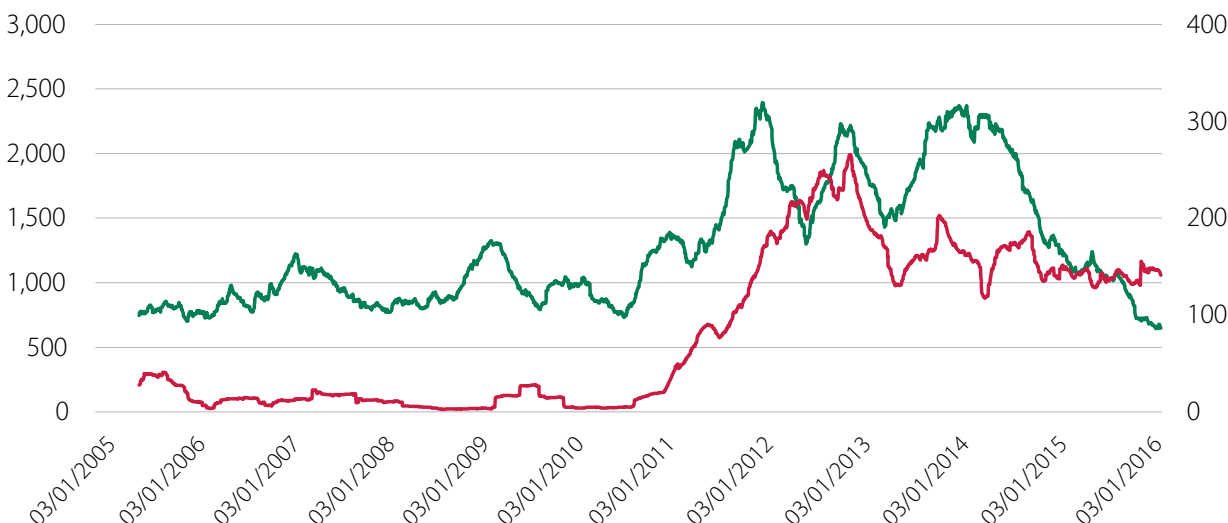

Turnover (per unit)

0.008

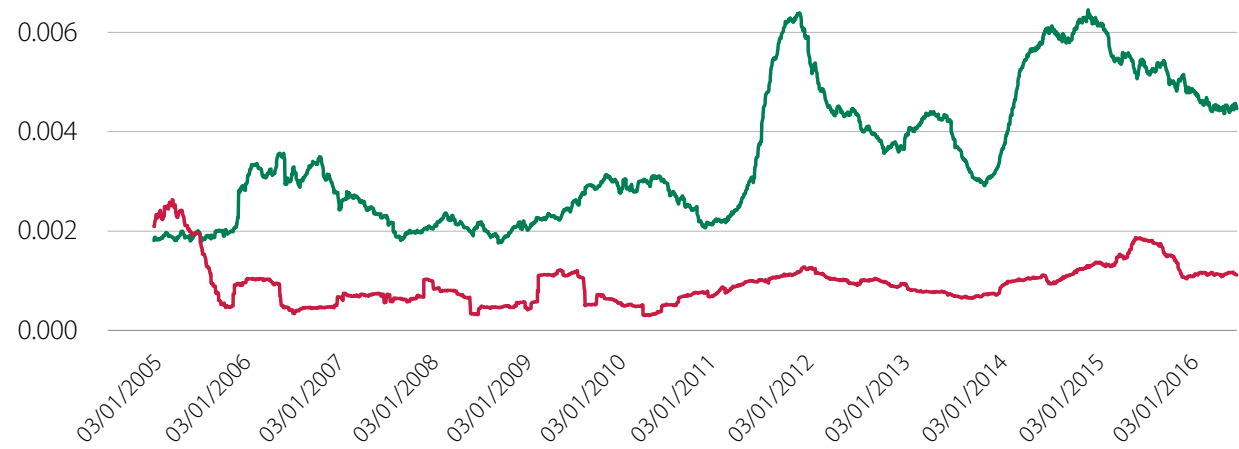


Proportion of traded bonds (per unit)

- Financial Non-financial

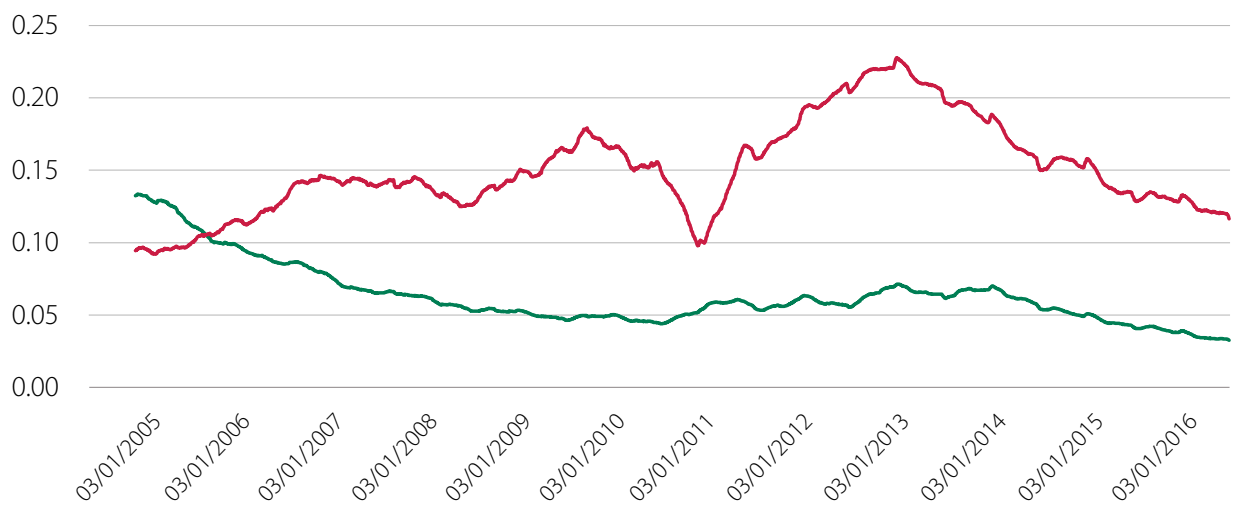

Amihud ratio (\%/100,000 euros)

- Financial — Non-financial (RHS)

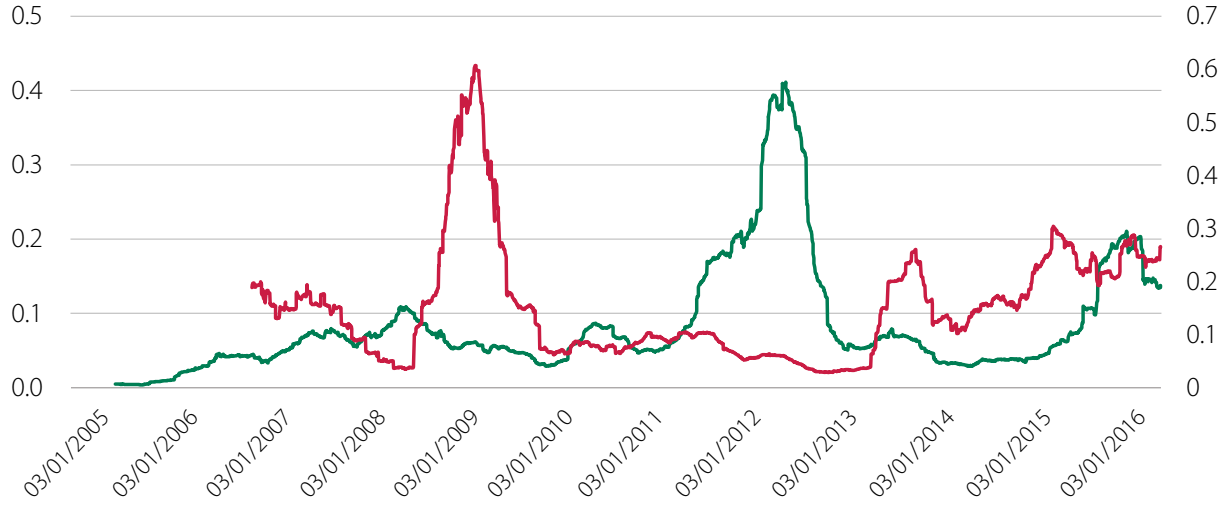

MEC

Government - Financial — Non-financial

3.0

2.5

2.0

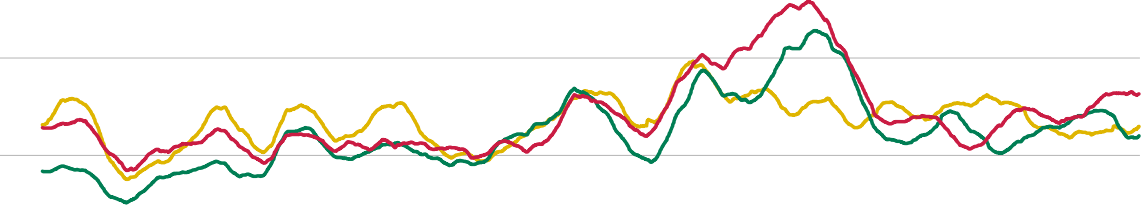

1.5

1.0

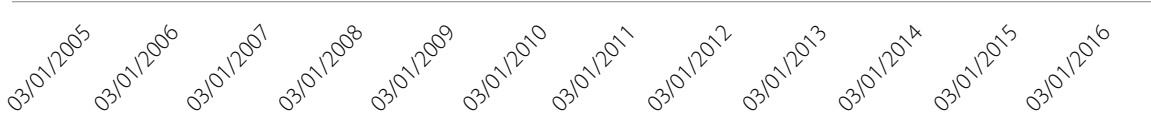

Source: AIAF, Bloomberg, CNMV and own calculations.

1 Six month averages. 
Financial debt trading volumes in AIAF were over 920 million euros between 2005 and 2011 on a daily basis. When TREM transactions are considered, average daily volume increases to 1.7 billion euros. These volumes were significantly high by mid2012, mid-2013 and in the second half of 2014. Non-financial debt volumes were much more reduced but we observe a substantial increase when we introduce TREM transactions (from 13 million euros a day to 146 million). It is important to mention the strong decline in trading volumes observed since the beginning of 2015. In the case of financial debt, trading volumes were well below 1 billion euros at the end of 2016, which are levels similar to those observed before the crisis (when TREM data was not available). Non-financial trading volumes have also decreased significantly although current levels are above pre-crisis levels.

Turnover ratios on financial debt increased $80 \%$ on average after 2011 , reaching a maximum in 2012 and 2015. This ratio has also shown a decreasing trend since June 2015 , but not so sharply as in the case of trading volumes. The decrease in the turnover ratio on financial debt may be partially influenced by the fact that we are considering issuance volumes and not outstanding volumes in the ratio. This is especially important in the case of securitisation where early repayment is frequent and, consequently, outstanding volumes used to be significantly lower than issuance volumes. Non-financial turnover debt has increased up to the beginning of 2016 and after that it has diminished.

The percentage of financial traded bonds has decreased during most of the sample period, from $13 \%$ in 2005 to $3.3 \%$ in 2016 . This ratio only showed a slight increase between 2010 and 2014 from $5 \%$ of existing bonds traded every day to $7 \%$. Since then, the ratio has diminished to less than $4 \%$. In the case of non-financial debt, we observe an irregular increasing path until mid-2013, when more than $20 \%$ of bonds were traded every day ( $9.5 \%$ at the beginning of the sample). After that, this percentage has declined to $12 \%$.

Amihud ratio has shown different patterns across sectors. In the case of non-financial bonds, this ratio reached a maximum at the beginning of 2009, in the context of the global financial crisis, and was broadly stable during the sovereign debt crisis. On the contrary, the financial bonds Amihud ratio only peaked significantly in 2012, in the moments of uncertainty related to the Spanish banking sector. During the past months, we have observed some deterioration of this ratio both for financial and non-financial bonds.

MEC ratios have shown peaks in several moments of uncertainty related to the European debt crisis although maximums have not been coincident across issuers. In the case of government bonds, the peak was reached by mid-2012, whereas in the case of private debt the peak was reached in the second half of 2013, being non-financial bonds the less resilient segment according to the values of this indicator. 


\section{$4 \quad$ The liquidity synthetic indicator (LSI)}

\subsection{Methodology}

In order to represent overall liquidity conditions of Spanish debt we have developed a unique and synthetic indicator based on the previous individual indicators. An increase of our proposed synthetic indicator points to a worsening in liquidity conditions, whereas a decline in the value of the indicator signals an improvement of liquidity. In our first step we transform individual indicators in a way such as higher values of individual indicators are related to poor liquidity conditions. In this sense we must use the inverse of volumes, turnover and percentage of traded bonds. Bid-ask spreads and Amihud ratios, by definition, are higher when liquidity is worse. In the case of the Market efficiency coefficient (MEC), we use deviations from one, following Broto and Lamas (2016), so that market resilience would increase under low values of the indicator and vice versa.

The second step transforms again all our individual liquidity indicators to ensure methodological harmonization, given the heterogeneity between them. Historically, academic papers have transformed variables using the mean and standard deviation. The most important inconvenience regarding this methodology is that it assumes that variables are normally distributed which usually is not the case of most of financial variables. For this reason we apply the transformation proposed by Holló et al. (2012), using the empirical cumulative distribution function (CDF). This methodology has been widely accepted in the construction of financial stress indices during the past years. ${ }^{11}$

Firstly, we order the values of our 14 individual indicators, so that each indicator $\mathrm{x}=\left(\mathrm{x}_{1}, \mathrm{x}_{2}, \ldots ., \mathrm{x}_{\mathrm{T}}\right)$, where $\mathrm{T}=601,{ }^{12}$ is transformed into its ordered sample $\left(\mathrm{x}_{[1]}, \mathrm{x}_{[2]}, \ldots\right.$ , $\left.\mathrm{x}_{[\mathrm{T}]}\right)$. The lowest value of the indicator corresponds to $\mathrm{x}_{[1]}$ and the highest value to $\mathrm{x}_{[\mathrm{T}]}$. If we denote $\mathrm{r}$ as the ranking assigned to each value of $\mathrm{x}_{\mathrm{t}}$, the transformed variables $z_{t}$ are then computed from the original variables $x_{t}$ on the basis of the empirical $\mathrm{CDF} F_{n}\left(x_{t}\right)$ as follows:

$z_{t=} F_{n}\left(x_{t}\right)= \begin{cases}\frac{r}{n}, & x_{[r]} \leq x_{t} \leq x_{[r+1]}, r=1,2, \ldots, n-1 \\ 1, & x_{[t]} \geq x_{[n]}\end{cases}$

for $t=1,2, \ldots, n$. The empirical CDF $\mathrm{F}_{\mathrm{n}}\left(\mathrm{x}^{*}\right)$ measures the total number of observations $\mathrm{x}_{\mathrm{t}}$ not exceeding a particular value $\mathrm{x}^{*}$ (which equals to the corresponding

11 See Cambón and Estévez (2016).

12 Given that we compute six month averages for each individual indicator, the number of weeks is 601 $(07 / 01 / 2005-12 / 30 / 2016)$. 
ranking number $\left.x^{*}\right)$ divided by the total number of observations in the sample (see Spanos 1999). The empirical CDF is hence a function which is non-decreasing and piecewise constant with jumps being multiples of $1 / n$ at the observed points. This results in transformed variables which are unit-free and measured on an ordinal scale with range $(0,1]$. The main inconvenience of this methodology is related to its simplicity and the fact that the distance between two consecutive points is limited to $1 / \mathrm{n}$, deriving in a certain loss of information. However, the problems related to outliers are avoided and the information of points near the average increase. In general terms, advantages of this methodology are very positive in this context.

This transformation is applied recursively over expanding samples in order to feature the real-time character of the indicator. The pre-recursion period for each variable runs from its first historical value until 26 December 2008, and all subsequent observations are transformed recursively on the basis of ordered samples recalculated with one new observation added at a time:

$F_{n+T}\left(x_{n+t}\right)=\left\{\begin{aligned} \frac{r}{n+T}, & x_{[r]} \leq x_{n+T} \leq x_{[r+1]}, r=1,2, \ldots, n-1, \ldots, n+T-1 \\ 1, & x_{n+T} \geq x_{[n+T]}\end{aligned}\right.$

for $T=1,2, \ldots, N$ with $N$ indicating the end of the full data sample.

Finally we aggregate the information of our 14 transformed individual liquidity indicators by means of a weighted average. There are several ways in order to compute the weights. We can proceed with a simple equal-weighted average, ${ }^{13}$ or we can use a principal components analysis or VAR models. ${ }^{14}$ The advantage of the principal component (PC) analysis is that with a limited number of PC we can capture most of the variance of the original series. The disadvantage of this procedure is that it's purely statistical and sometimes it's complicated to give an economic or financial intuition of the results. Other alternative methodologies use VAR models to obtain the weights in order to reach the final indicator. Some of them also take into account the correlation between the series.

In our study, the PC procedure for total debt markets tends to overestimate the weight of non-financial debt indicators. For that reason, we compute PC weights but we adjust them by taking into account the relevance of government, financial and non-financial debt on total issuance volumes and the total amount of outstanding debt in the markets (see table A.3). In addition, we perform PCA to obtain two specific liquidity indicators for financial and non-financial corporations (each indicator is composed by six individual indicators). According to table 3, the four PCs are able to explain $89 \%$ of total variance of the original series in the case of financial entities and $91 \%$ in the case of non-financial corporations. We follow the methodology of the OECD $(2008)^{15}$ and Broto and Lamas (2016) to capture the information of the

13 See the AMF (2015).

14 See the FCA (2016).

15 Following this approach, once we obtain the factor loadings of the four PC's, we compute their squared values (their sum is equal to one). Next, we construct an intermediate composite index in two steps: (i) we select the highest factor loading for each of the six indicators, and (ii) we compute the 
first four PCs and obtain a unique vector of weights to estimate a liquidity indicator for each private debt sector (financial and non-financial). The final weights can be found in table A.4.

Principal component analysis

TABLE 4

\begin{tabular}{lrrrrrrr} 
& \multicolumn{2}{c}{ Financial entities } & \multicolumn{3}{c}{ Non-financial corporations } \\
\hline $\begin{array}{l}\text { Principal } \\
\text { component }\end{array}$ & Eigenvalues & $\begin{array}{c}\text { \% of total } \\
\text { variance }\end{array}$ & $\begin{array}{c}\text { Cumulative } \\
\text { variance }\end{array}$ & $\begin{array}{r}\text { Principal Eigenvalues } \\
\text { component }\end{array}$ & $\begin{array}{r}\text { \% of total Cumulative } \\
\text { variance }\end{array}$ & variance \\
\hline 1 & 2.553 & 42.54 & 42.54 & 1 & 2.342 & 39.03 & 39.03 \\
\hline 2 & 1.370 & 22.84 & 65.38 & 2 & 1.419 & 23.65 & 62.68 \\
\hline 3 & 0.820 & 13.66 & 79.04 & 3 & 1.214 & 20.23 & 82.91 \\
\hline 4 & 0.608 & 10.14 & 89.18 & 4 & 0.503 & 8.38 & 91.29 \\
\hline 5 & 0.353 & 5.88 & 95.06 & 5 & 0.371 & 6.19 & 97.48 \\
\hline 6 & 0.296 & 4.94 & 100 & 6 & 0.151 & 2.52 & 100 \\
\hline
\end{tabular}

Source: CNMV.

\subsection{Results}

\subsubsection{Total market liquidity indicator}

Figure 6 shows the results of the liquidity synthetic indicator of Spanish debt. We can measure the contribution of each liquidity characteristic to the indicator as well as the contribution of each sector as it is presented below. According to our results, we observe three moments where liquidity conditions have worsened significantly. The moment of worst liquidity conditions in the market was reached at the end of 2008 when Lehman Brothers collapsed. The value of the indicator was 0.84 in that moment. Other peaks of illiquidity in the market (in 2010 and 2012) can be related to different episodes of uncertainty in the context of the European sovereign debt crisis. More recently the indicator points to some deterioration in bond market liquidity that can be associated with more capital demanding regulations ${ }^{16}$ as well as with the current context of low interest rate environment and the assets purchase programmes of the ECB that may be affecting bond trading in certain segments of the market.

share of each one over the sum of the chosen factor loadings for each PC. Finally, we multiply these loadings by the proportion of the variance that each of the four PC explains (the new loadings add up to one).

16 Regulation implemented in response to the global financial crisis to ensure the safety and soundness of core intermediaries has discouraged them from market making as principal activity -although this may also reflect greater risk aversion on their part. 


\section{By liquidity characteristics}
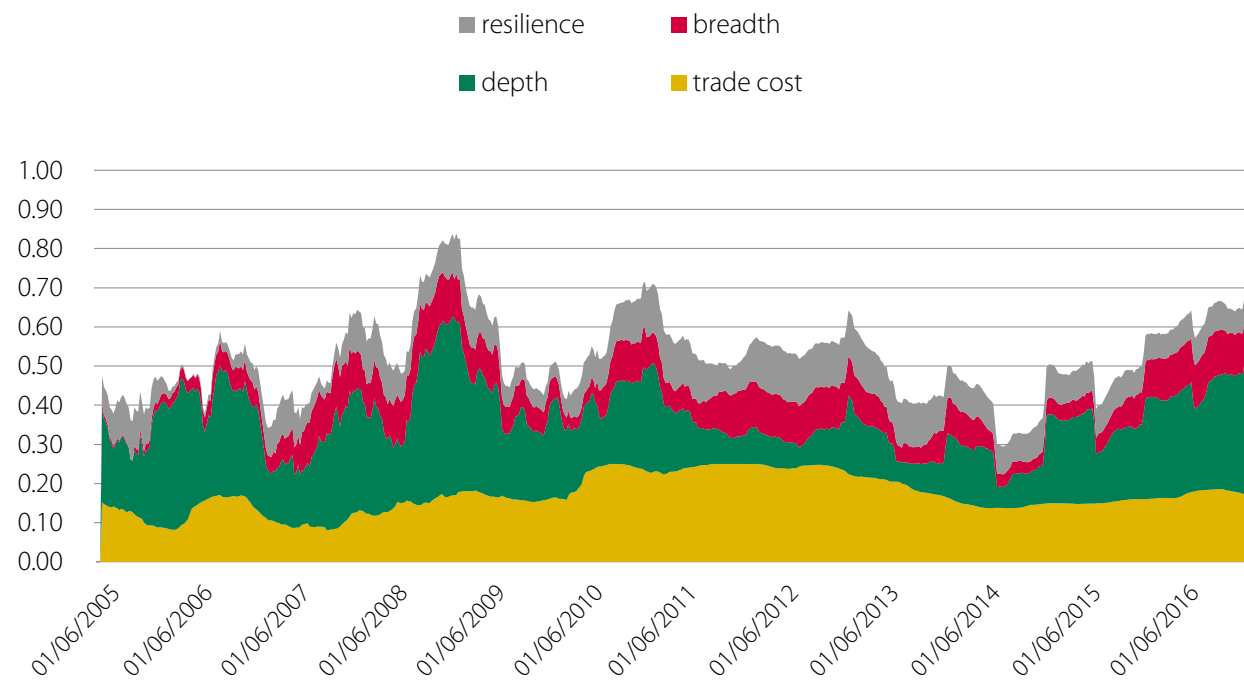

By sector

- Non-financial

- Financial

Government

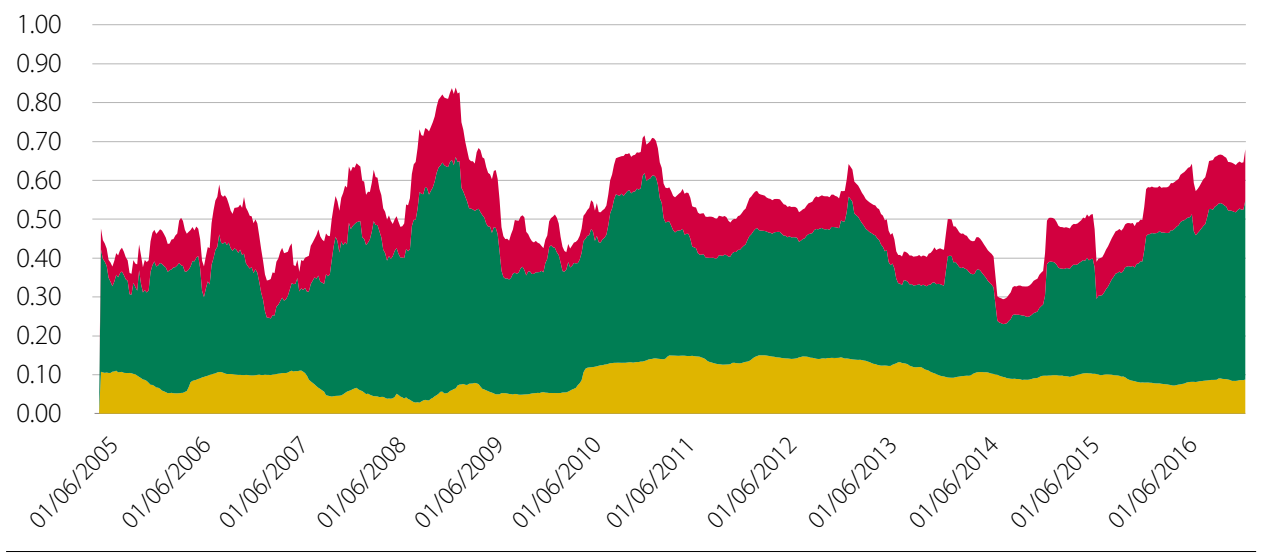

Source: CNMV.

It is very interesting to see that contributions to illiquidity have changed significantly over time, especially during stress periods. At the end of 2008 the worsening in liquidity conditions was originated by the deterioration of market depth and resilience, mainly in the financial sector. However, illiquidity of bond markets in the context of the European debt crisis was more related to the increase of transaction costs and, to a lesser extent, to a depth and resilience weakness. The contributions of government and financial debt to the upswing in the indicator were predominant. Finally, the worsening in liquidity conditions we have observed for the last months has to do mainly with financial firms and with lower trading volumes, that is, with the worsening of market depth. Market breadth is also weakening. 
Given the trend we have been observing during the past years related to the increasing trading volumes of Spanish assets (bonds and equities) in foreign and OTC markets, we have compared our global Spanish bonds liquidity indicator with a "domestic liquidity indicator" which only considers domestic transactions (AIAF transactions). Price based indicators remain the same in this context. The difference between both liquidity indicators are presented in figure $7 .{ }^{17}$ It is straightforward to see that liquidity conditions of Spanish bonds are significantly worse when we don't consider foreign and OTC transactions. In fact, according to the results of the domestic liquidity indicator, the moment with worst liquidity conditions in Spanish markets was reached in the second half of 2012 (and not in 2008) just after the crisis related to our banking system. After this period of uncertainty, both indicators have reduced the gap between them showing a similar pattern given the fact that recent deterioration of liquidity is determined by global elements such as the context of low interest rates or regulation.

\section{The liquidity indicator: Spanish market versus Spanish issuers}

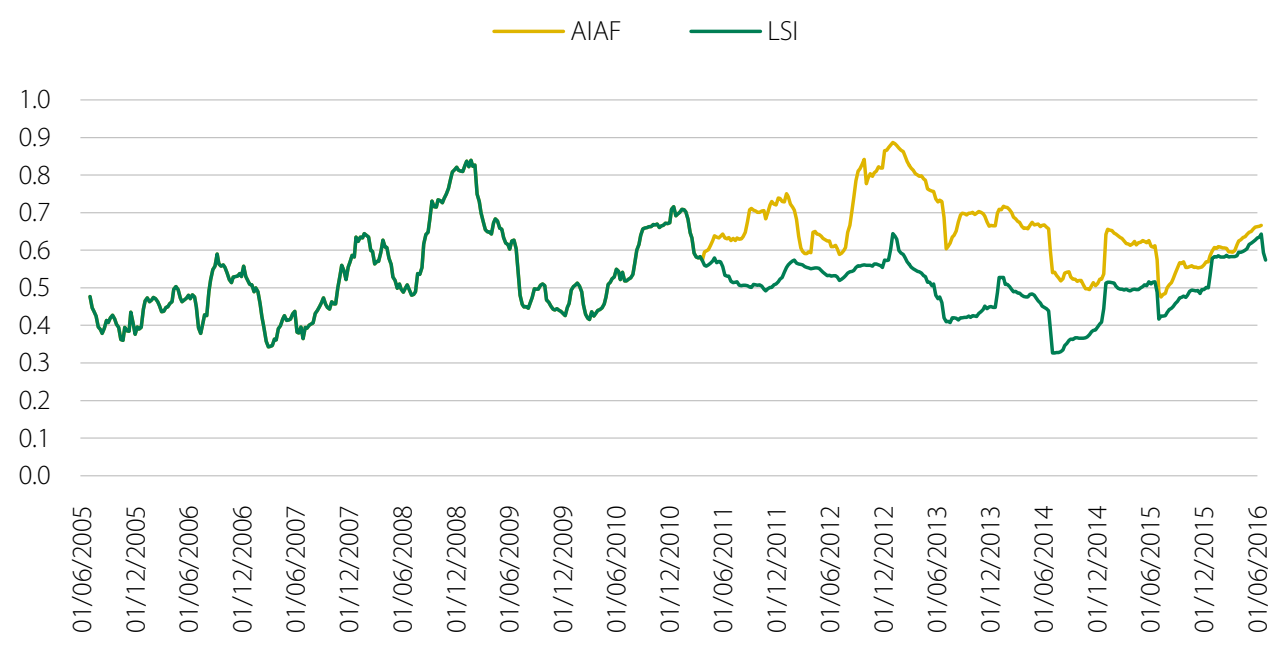

Source: CNMV.

\subsubsection{Sectoral liquidity indicators (financial and non-financial)}

Besides the liquidity indicator for the whole fixed-income market, we present two additional liquidity indicators for the private sectors of the economy (the financial and non-financial sector). We must bear in mind that we have aggregated the six individual liquidity indicators of each sector applying the PCA methodology. The results are presented in figure 8. It is interesting to see and compare different moments of illiquidity of both sectors as well as the more recent trend of liquidity conditions. In general, the level of the indicator for the financial sector is higher than the level observed for the non-financial corporations: $47 \%$ of the observations of the financial liquidity indicator are above 0.60 versus only $7 \%$ of the non-financial indicator. One potential explanation for this may be related to the significant number of issues of financial entities that, in general, are also smaller in size with

17 It is necessary to bear in mind that foreign and OTC transactions data is only available since 2011. 
respect to non-financial issues. The intuition here is that the more number of outstanding issues (many of them structured bonds) the less liquid the market is. In bond markets, trading usually tends to concentrate only on a specific pool of assets.

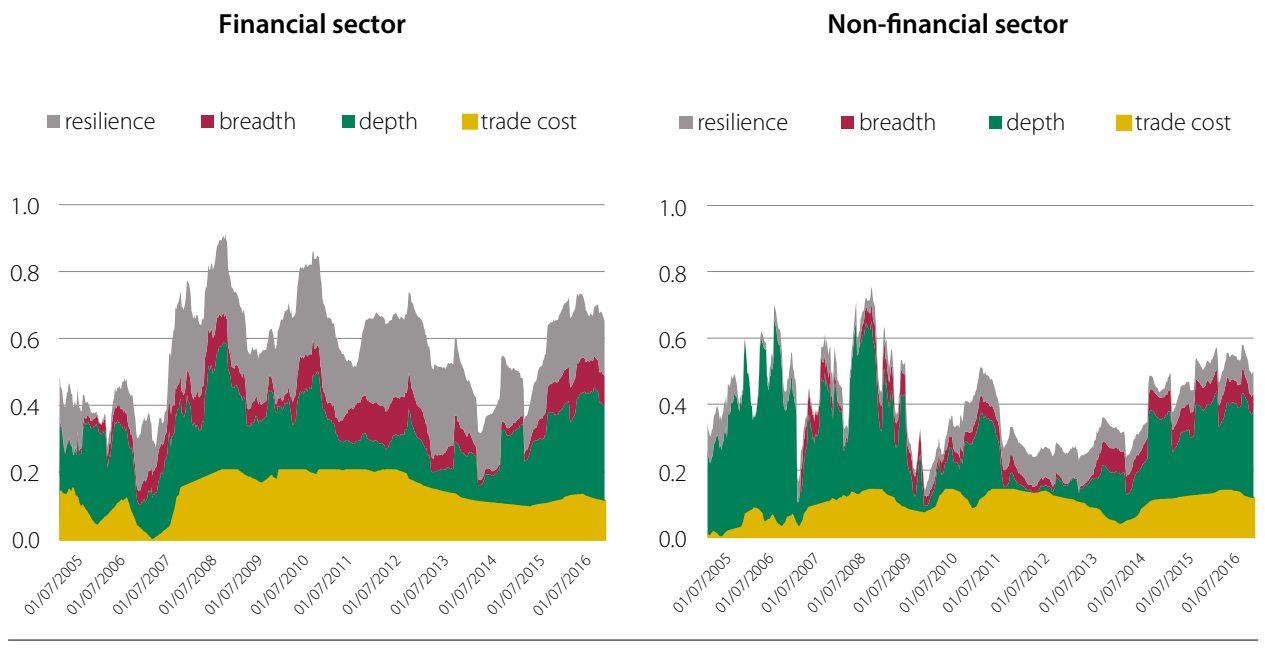

Source: CNMV.

According to the results presented in figure 8, it is possible to see that the moment of worst liquidity conditions in bond markets was at the end of 2008: the financial sector liquidity indicator reached a maximum of 0.91 and the non-financial sector liquidity indicator reached a level of 0.76 . After that, we also observe several episodes of worsening in liquidity conditions during the sovereign debt crisis that were more significant in the case of financial corporations. After a sizeable improvement of liquidity, we observe a new deterioration in the indicator to 0.70 for financial bonds and 0.59 for non-financial bonds that can be partially related to the ongoing asset purchase programmes of the ECB.

Regarding liquidity characteristics, we see that depth dimension and, to a lesser extent transaction costs, are relevant to represent all periods of liquidity drops both for financial and non-financial corporations. In this sense, the contraction of trading volumes and the decrease of the proportion of bonds that are traded every day are key issues to explain the worsening of liquidity conditions. We also observe that resilience and breadth are also important to explain liquidity trends in the financial sector but they are not very relevant for non-financial companies. 


\section{$5 \quad$ Evaluation of the LSI}

\subsection{The liquidity synthetic indicator and the Spanish financial stress indicator}

The Spanish financial market stress indicator ${ }^{18}$ (FMSI) tries to quantify the level of stress in six segments of the financial system and aggregates the information into a unique number that represents the Spanish systemic risk. This measure is very useful in the context of a financial stability analysis and includes four types of variables that are good proxies of market stress: liquidity, credit risk, volatility and price drop indicators. It is important to mention that information related to liquidity in the FMSI is only related to transaction costs (bid-ask spreads) for equities (Ibex 35) and for the government bond (10Y bond). Our LSI includes transaction costs (not only for the $10 Y$ government bond) and other indicators representing liquidity characteristics such as depth, breadth and market resilience.

Having in mind the differences in the methodology, the determinants and the interpretation of both indicators, we think that it can be interesting to compare the FMSI and the LSI and check coincidences and divergences across our sample period. A priori, peaks in the systemic risk indicator should be accompanied by peaks in the liquidity indicator given that when financial stress is high we usually observe high price volatility, high credit spreads and liquidity drops. However, peaks in the liquidity indicator do not necessarily point to a period of high and widespread stress in the financial system: it can be a temporary reduction of liquidity with no systemic risks involved.

Figure 9, which depicts the FMSI and the LSI, shows a coincidence between both indicators at the end of 2008, when Lehman Brothers collapsed. Both the FMSI and the LSI reached their historical peaks at 0.88 and 0.84 respectively. The second peak of the FMSI was reached by mid-2012 just after the moment where the Spanish government asked for financial assistance in order to capitalise the banking system. This maximum was originated by a huge credit risk premiums (of government and financial entities) and extremely high volatility. Our LSI showed a peak only a few months later (at the end of 2012) because trading volumes were high during most of the sovereign crisis period and only decreased at the end of 2012. In addition, the LSI indicator exhibited a peak in 2010, a loss of liquidity in bond markets that was not related to any systemic risk episode. This peak was related to the first step of the European sovereign debt crisis and reflects the worsening of transaction costs in the market as well as the deterioration of market resilience. However, this peak must be interpreted with caution because it may be affected by the lack of TREM transactions

18 See Cambón and Estévez (2016). 
before 2011. Our LSI could be overestimating illiquity before 2011 because of the lower implicit volumes of our data base.

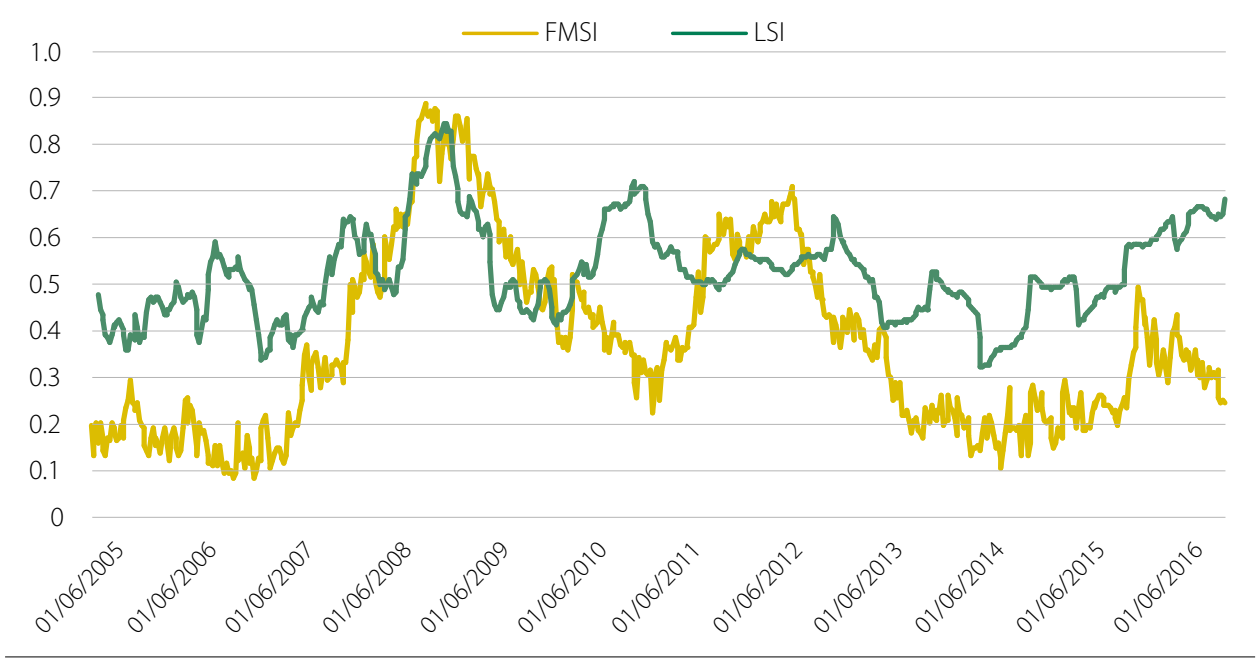

Source: CNMV.

In general both indicators follow similar trends except in the period 2010-2011 given their structural differences and the lack of foreign transactions data during this period as we explained earlier. In fact, correlation between the FMSI and the LSI is high (slightly below o.60). ${ }^{19}$ It is important to highlight the more recent behaviour of both indicators. We have seen an improvement of liquidity conditions in bond markets and also in the level of financial stress from the end of 2012 until 2014. During the last months we have observed a deterioration of bond market liquidity and also a higher level of stress originated by a wide variety of elements: the uncertainty on global economic growth and European banking resilience, the Brexit process and other political sources of uncertainty. It is reasonable to think that this worsening in bond liquidity conditions is partially related to the increase in the general level of stress of the financial system. However, it is possible that the increasing trend in the LSI can be explained in terms of other structural elements (new regulations after the crisis, the context of low interest rates, ECB's asset purchase programmes...).

\subsection{Relationship between the liquidity indicator and liquidity performance of Spanish mutual fund portfolios}

Liquidity risk analysis has been relevant for CNMV since the beginning of the global financial crisis because its potential impact on institutions under its supervision, like investment funds. In the context of the crisis, CNMV started to quantify the level of illiquid assets ${ }^{20}$ in the private fixed-income portfolio of mutual funds in or- 
der to anticipate potential problems in the case of a sudden increase in the volume of redemptions. As figure 10 points out, this measure reached a maximum at the end of 2008 , when the volume of illiquid assets represented $37 \%$ of total private fixed-income assets of mutual funds (and 9\% of total mutual fund assets). After this maximum, the level and the proportion of illiquid assets have decreased significantly as a consequence of the improvement of the liquidity conditions of the market and especially of the change in the portfolio composition of mutual funds. Since the beginning of 2015, the proportion of illiquid assets ranges between $7 \%$ and $9 \%$ of total private fixed-income portfolio (and between $1 \%$ and $1.4 \%$ of total mutual fund assets).

The comparison between the proportion of illiquid assets in a mutual fund portfolio and the (private debt) LSI suggests a similar trend for both measures until the end of 2013. We observe a maximum at the end of 2008 (or the beginning of 2009) when liquidity worsened significantly in bond markets and a substantial recovery after that. Since 2014 the trend of these indicators diverges: the LSI points out to a worsening in bond market liquidity whereas the proportion of liquid assets remains broadly stable. Apart from differences in the consideration of liquid asset of both measures, the divergence could be explained in terms of changes in the portfolio composition. Mutual fund managers are investing more (in absolute and relative terms) in fixed-income assets that are more liquid than the average Spanish bond. According to the data that CNMV receives for supervisory purposes, we see an increasing relevance of foreign assets in the portfolio of mutual funds, especially of private debt ${ }^{21}$ and CIS investments.

\section{The liquidity indicator versus illiquid assets in investment funds' portfolio}

FIGURE 10

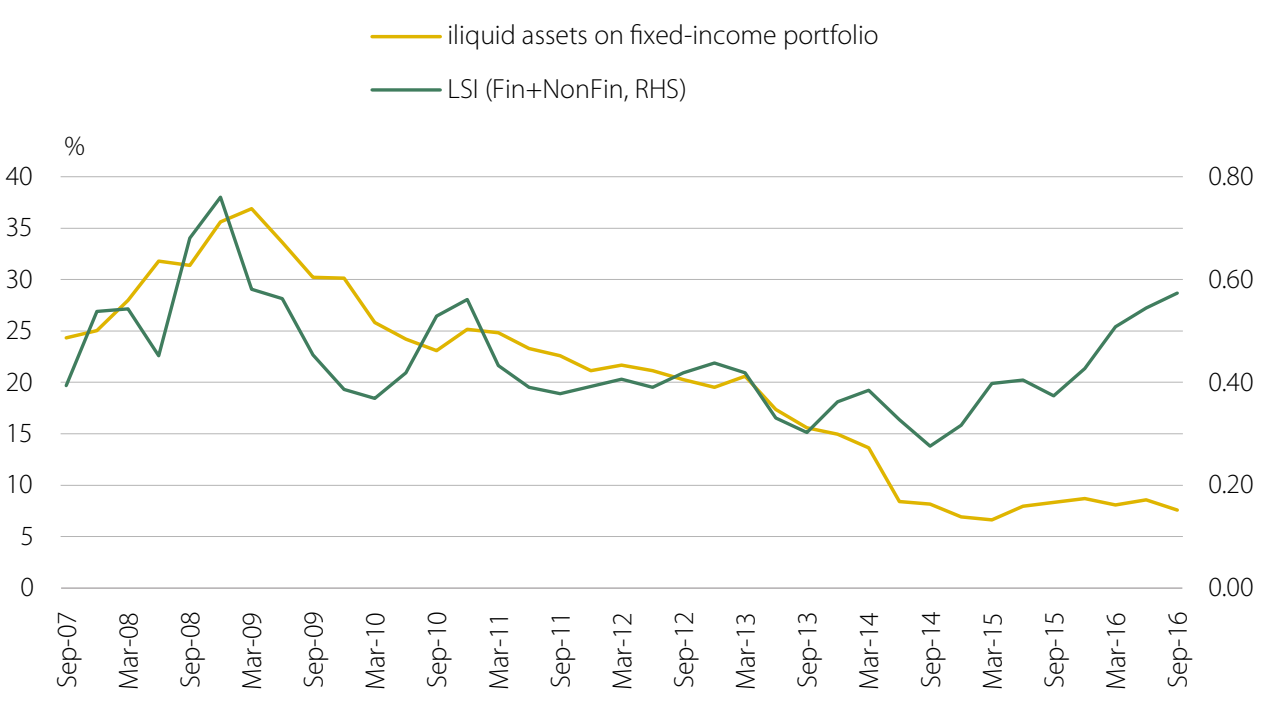

Source: CNMV.

21 Mutual fund investment on foreign listed corporate debt has increased from 8.1 billion euros in Dec2013 to 32.4 billion in June-2016. In the same period, the investment on foreign public debt has increased from 3.4 billion euros to 18 billion, in contrast with the holdings of total domestic debt instruments (from 79.5 billion euros to 60.6 billion). 


\subsection{The LSI and and ESMA criteria for liquid assets}

The Markets in Financial Instruments Regulation ${ }^{22}$ (MiFIR) introduces pre-trade and post-trade transparency requirements for trading venues and investment firms with respect to bonds, structured finance products, emission allowances and derivatives. These requirements are subject to certain conditions and waivers. This regulation empowers the European Commission to adopt, following a submission of draft regulatory technical standards (RTS) by the European Securities Market Authority (ESMA), a Regulation specifying those pre- and post-trade transparency requirements. ESMA submitted the draft RTS to the Commission on 28 September 2015. Regarding liquidity assessment for bonds, ESMA proposed a quarterly assessment in which each individual bond would be declared liquid if the following three quantitative criteria are met on a cumulative basis:

i. Average daily notional amount traded $\geq$ EUR 100,000;

ii. Average daily number of trades $\geq 2$

iii. Percentage of days traded over the period considered $\geq 80 \%$

On April 2016, the Commission notified ESMA its intention to endorse this draft standard subject to a number of changes. In general, the Commission proposed a more cautious approach: in relation to the average daily number of trades above with which a bond market is deemed liquid, the Commission suggested to set the liquidity threshold initially at 15 daily trades and advocated a gradual decrease of the daily trades that denote a liquid market according to four successive thresholds (S 1: 15 daily trades, $S_{2}$ : 10 daily trades, $S_{3}: 7$ daily trades and $S_{4}: 2$ daily trades).

On May 2016, ESMA submitted a formal opinion on the Commission letter, retaining most of the amendments proposed by the Commission and proposing an automatic phase-in in four distinct steps. Finally, on July 2016, the Commission published the delegated regulation supplementing MiFIR regulation, indicating that it supports setting out a clear phase-in schedule for the liquidity standards (and also the waiver thresholds) that gives clarity to market participants, but the process should not be automatic. Under a more cautious approach, the Commission states that before considering a transition to a subsequent threshold, ESMA carries out a comprehensive assessment analysing the evolution of trading volumes in non-equity instruments covered by the pre-trade transparency obligations, the impact on liquidity providers of current thresholds and other factors potentially affecting liquidity or market making activity. Only when ESMA's analysis satisfies that liquidity and market making activity in non-equity markets will not be negatively affected by a subsequence move, the move to the next threshold will be achieved.

In this section, we apply the criteria originally proposed by ESMA to our database and compare the results with the LSI. This exercise is only for illustrative purposes and not comparable with other similar works jointly performed at a European level

22 Regulation (EU) No 600/2014. 
because of the following reasons: (i) we use a different bond universe, ${ }^{23}$ (ii) we have a longer period of time and (iii) our exercise may be potentially affected by the criteria applied to remove outliers. ${ }^{24}$

Having in mind these caveats, figure 11 presents the number of bonds (financial and non-financial) that meets ESMA criteria on a quarterly basis. According to the results, the number of liquid bonds was relatively stable until 2010, when the first episode of turbulences related to the European debt crisis happened. During these years, the number of liquid bonds ranked between 20 and 30 , most of them financial bonds. After 2010, the number of liquid bonds increased significantly, reaching a maximum exceeding 100 (67 financial and 41 non-financial) in the first quarter of 2013. The inclusion of OTC and foreign markets transactions in our sample since 2011 has had an impact in this measure, especially in non-financial bonds. It seems to be the case that bond trading in domestic fixed-income markets is characterised by lower trade sizes whereas OTC and foreign markets trades are made up of bigger and more frequent trades.

After the maximum, the number of liquid bonds under ESMA criteria has shown a decreasing trend, which is compatible with the evolution of the LSI that signals a worsening in liquidity conditions during the last two years. The number of liquid bonds was 30 at the end of 2016, slightly higher than levels that those observed during the first half of our sample.

Number of Spanish liquid bonds under ESMA criteria

FIGURE 11

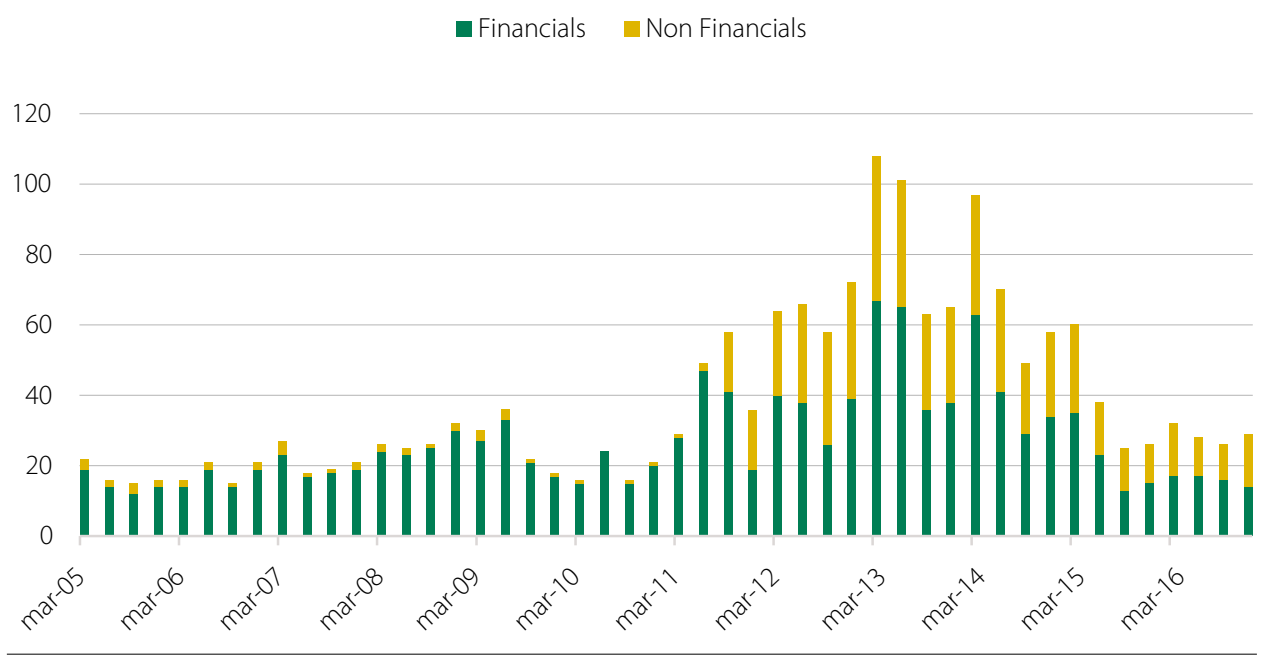

Source: CNMV.

23 We have used bonds issued by Spanish issuers that are similar but not identical to the universe usually employed in other European task forces, where the scope is bonds for which every National Authority is the competent authority according to ESMA's Instruments Reference Data System.

24 See footnote No 9. 


\subsection{The liquidity approach under ESMA's work: a robustness analysis}

The evaluation of corporate bond liquidity at a European level is also being conducted in ESMA with the work of members of different European securities markets authorities. This (ongoing) work is very positive because it is the first study to provide a European perspective on bond liquidity applying the same methodology in each country. Although several specific aspects related to the methodology are still being discussed in the group, in this section we address the general approach of this project and explain the main differences with respect to the methodology applied in this paper.

ESMA methodology presents many similarities with the one proposed here, but there are relevant differences that may have an impact on the evaluation of liquidity. Both liquidity analysis are relevant and, in some sense, complementary, but it's very important to bear in mind that conclusions are always based on a particular set of data and a particular methodology. In this case, the European indicator and our indicator are similar in the sense that both are based on a set of individual liquidity indicators that are aggregated in a single value. However, it's important to highlight the differences related to the selection of bonds, the individual liquidity indicators, the sample period and the transactions database. This section presents the main characteristics of the European analysis and describes the differences with respect to our study in order to understand the potential results under both approaches. As a robustness check exercise, we will test how sensitive are the results depending on the data and the methodology applied. The main differences between the ESMA approach and our study are listed below:

- $\quad$ Bond universe. ESMA's approach excludes structured bonds and bonds issued by domestic issuers where the competent authority is not the domestic authority. In the analysis of CNMV, liquidity conditions are addressed from a broader perspective: we include all bonds issued by domestic issues irrespective where they trade and also include structured products. We don't have any specific reason to exclude structured bonds from the analysis given the need to illustrate the impact of their illiquid nature on global liquidity and also given their increasing relevance over the last years. The number of bonds selected by the ESMA approach is near 4,000, approximately 2,000 less that our number of bonds (existing during 2012-2016).

- Transactions database: In our study, we have used information from AIAF (the regulated Spanish fixed-income market) since 2005 and TREM information since 2011 for those transactions executed in other foreign regulated markets or OTC transactions. ESMA's approach will only use TREM transactions during 2012-2016. TREM information is available for all European countries since 2011-2012 but some concerns on misreporting still persist.

- Sample period. CNMV's approach uses information since 2005 and ESMA's study will use information since 2012. Under the ESMA analysis we will be able to compare recent liquidity trends with those perceived in some episodes related to the European debt crisis (in 2012) but it won't be possible to establish a comparison with the liquidity drops in the context of the global financial crisis (in 2008). 
- Selection of individual liquidity indicators. The selection of individual indicators is relatively similar to our list: 4 out of 6 indicators we have included in our analysis will be computed under the ESMA approach (bid-ask spreads, turnover, MEC and Amihud ratio). However, absolute trading volumes and percentage of traded bonds, that are relevant variables to explain the recent deterioration of bond market liquidity, are not considered at a European level. The European study will include two additional measures: (i) the zero trading days indicator and (ii) the Roll measure. The zero trading days indicator reports the number of days where the bond did not trade in a given period (usually three months). The result of this indicator could be correlated with the result of the percentage of traded bonds. ${ }^{25}$ The Roll measure is based on the autocorrelation of observed prices. ${ }^{26}$ The intuition of the measure is that if prices are driven by a fundamental component and a transitory (i.e. liquidity) component, then the autocorrelation of prices can be a measure of the transitory component.

- $\quad$ Methodology issues: The methodology to transform and aggregate liquidity indicators is still pending. There are several options to transform the indicators (CFD's, normal distribution...) and to aggregate them (simple averages, weighted averages, PCA's...). These options present several pros and cons that will be discussed in the future.

Figure 12 presents the results of the individual liquidity indicators for Spanish bonds under ESMA's criteria. The final version of these indicators may be slightly different because specific aspects of the methodology may change. However, this preliminary version of the indicators is also informative. What we see is that the evolution related to transaction costs indicators (bid ask spreads) and resilience (MEC) is similar to the trend presented in section 3.3. In the case of bid ask spreads, we observe a decreasing pattern since 2012 in financial bonds whereas in the case of non-financial, the spreads have been low during most part of the sample, although they have increased significantly during 2016. In the case of the MEC indicator, we observe higher values (less liquidity) both for financial and non-financial in 2012 and 2013 and lower and stable values since 2014 .

25 However, it's necessary to bear in mind that the zero trading days indicator only includes information of bonds actively traded whereas the percentage of traded bonds indicator tries to include information of those bonds with no transactions.

$26 \operatorname{Roll}_{t}=2 \sqrt{-\operatorname{cov}\left(R_{i}, R_{i-1}\right)}$, where " $\mathrm{t}$ " is the time period for which the measure is calculated. If the covariance is positive, the observation is discarded. Roll measure is defined using a rolling window of 21 trading days. 
Bid-ask spread (per unit)

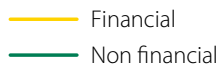

0.025

0.020

0.015

0.010

0.005

0.000

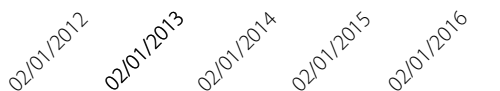

Turnover (per unit)

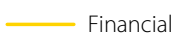

Non financial

0.020

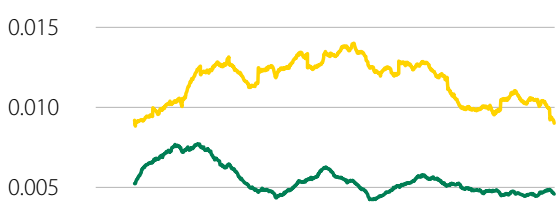

0.000

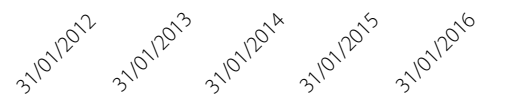

Amihud ratio $(\% / 100.000 €)$

_- Financial

- Non financial

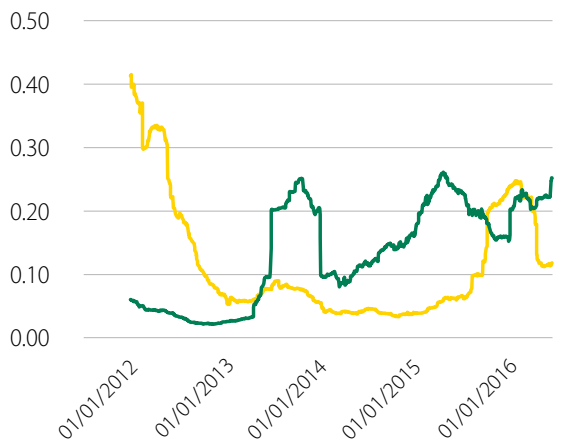

MEC

Financial

Non financial

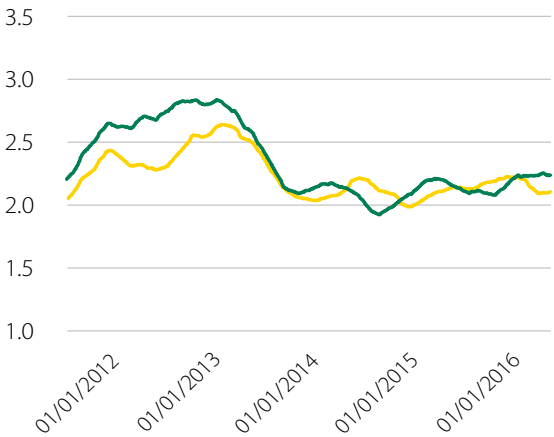

Zero trading days

- Financial

Non financial (RHS)

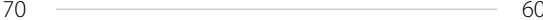

69

68

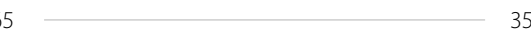

Roll measure

Financial

Non financial

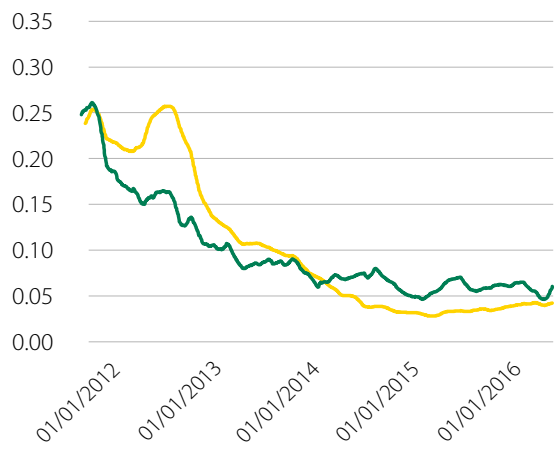

Source: CNMV. 6 months averages except in zero trading days indicator that shows the number of days (on average) without transactions during the last quarter. 
The two liquidity indicators representing market depth (turnover ratio and zero trading days) show that liquidity has worsened over the last years. Non-financial bonds turnover ratio has decreased during most of the period reaching a minimum at the end of 2016. Financial bonds turnover ratio increased until mid-2014 and after that has experienced a strong decline. The zero trading days indicator, that shows (for a given bond and period of time $)^{27}$ the number of days without transactions, decreased significantly during 2012 signalling an improvement of liquidity conditions both for financial and non-financial bonds. After a relative stable trend in 2013, the number of days without transactions started to increase. In the case of financial bonds, the number of no-trading days at the end of the sample reached a maximum (near 69 days on average), whereas in the case of non-financial bonds, the increase was higher in absolute terms but the number of days without transactions at the end of 2016 (near 50 days on average) was below the level of 2012 (more than 55 days). In general, depth indicators under ESMA's approach show a deterioration of liquidity in bond markets that is compatible with our results although the drop of liquidity appears to be less significant. The main reason for that have to do with the exclusion of two relevant depth indicators: trading volumes (in absolute terms) and the proportion of bonds without any trading that explains a significant part of the recent deterioration of liquidity in our LSI.

Finally, the liquidity indicators related to breadth (Amihud ratio and Roll measure) suggests a mixed picture on liquidity. Whereas the Amihud ratio shows a recent deterioration of liquidity, similar to our results presented in section 3.3, Roll indicator reveals an improvement of liquidity over the last years both for financial and non-financial bonds.

In general, we observe that: (i) indicators related to transaction costs and resilience are similar to our liquidity indicators, (ii) indicators representing depth signal a worsening in bond markets liquidity, although less significant that our LSI given the exclusion of two relevant indicators and the universe of structured bonds, (iii) indicators representing breadth are also similar in terms of the Amihud ratio, but ESMA adds an additional indicator (Roll) that shows a significant improvement of liquidity over the past years. In aggregate terms, we could say that the analysis of bond liquidity under ESMA's approach suggests a deterioration of bond liquidity over the past years, although less significant than in the proposed LSI.

27 In our case, three months. 



\section{Conclusions}

Financial markets have been affected by a number of structural changes over the past few years. Regulation implemented in response to the global financial crisis to ensure the safety and soundness of core intermediaries has discouraged them from market making as principal activity -although this may also reflect greater risk aversion on their part-. Additionally, innovation has generated a broad trend towards fast electronic trading that may be impacting on market liquidity. Finally, current extremely low interest rates environment may be sustaining liquidity conditions in certain segments of the market, but the ECB purchase programmes may be detrimental for liquidity. These issues and the numerous episodes of volatility may have introduced some fragility in the market liquidity performance.

Assessing liquidity in fixed-income markets is not easy given the idiosyncratic nature of these markets, with a great variety of instruments and a big proportion of bonds that is not traded every day. There are several bond characteristics that are positive for liquidity; (i) bond standardisation (standard terms increase price transparency and attract a larger pool of buyers and sellers), (ii) benchmark consideration (again, it implies higher trading volumes), (iii) availability of hedges (investors prefer to buy assets that can be easily hedged) and (iv) collateral eligibility consideration (investors are interested in assets that can be posted as collateral). There are also negative elements for bond liquidity: (i) bond exposure to tail events (investor's demand for assets exposed to tail risks decreases in moments of stress), (ii) bond complexity (investors are less interested in assets difficult to understand and whose risks are difficult to manage) and (iii) low sensitivity of bonds to news (in general, active investors want to profit from information).

Given this background, assessing and measuring liquidity conditions has become increasingly important over the past years. It is important to know if debt markets liquidity has worsened after the global financial crisis as some participants in the markets suggest. In this paper, we propose a synthetic liquidity indicator of Spanish debt that describes several dimensions of liquidity (depth, breadth, transaction costs and resilience); by applying the methodology suggested by Broto and Lamas in 2016 for US debt. We have computed several price- and transaction-metrics for public and corporate debt since 2005 .

According to our results, we observe three moments where liquidity conditions have worsened significantly. The moment of worst liquidity conditions in the market was reached at the end of 2008 when Lehman Brothers collapsed. The value of the indicator was 0.84 in that moment. Other peaks of illiquidity in the market (in 2010 and 2012) can be related to different episodes of uncertainty in the context of the European sovereign debt crisis. More recently the indicator points to some deterioration in bond market liquidity that can be associated with more capital 
demanding regulations, the current context of a low interest rate environment (only higher yield bonds may be attractive) and the ECB's fixed-income purchase programmes.

Contributions to illiquidity have changed significantly over time, especially during stress periods. At the end of 2008 a worsening in liquidity conditions was originated by the deterioration of market depth and resilience, mainly in the financial sector. However, illiquidity of bond markets in the context of the European debt crisis was more related to the increase of transaction costs and, to a lesser extent, to depth and resilience weakness. The contributions of government and financial debt to the upswing in the indicator were predominant. More recently, the worsening in liquidity conditions has to do mainly with financial firms and with lower trading volumes (depth). Our sectoral indicators show that the segment of financial bonds is more illiquid than the segment of non-financial bonds. Our intuition is that the proliferation of structured products issued by financial entities since the crisis may explain a significant part of this difference. We also observe that lower trading volumes are key issues to explain the deterioration of liquidity of both (financial and non-financial) bonds during the past years.

According to the evaluation of this indicator, we have observed that periods of high stress in Spanish financial markets are accompanied by poor liquidity conditions. However, the opposite trend is not always true: we can detect a worsening in liquidity but not a general increase in systemic risk. We have also compared the evolution of the LSI with the proportion of illiquid assets in the mutual fund portfolio. We observe similar patterns during most part of the period. However, since 2014 both indicators present different trends: the LSI points to a deterioration in liquidity whereas the proportion of illiquid assets in the fund portfolio remains stable. The increasing foreign debt investment of mutual funds could partially explain this fact. Finally, we have computed the number of Spanish liquid bonds according to ESMA's criteria in the context of the new transparency requirements that MiFIR has established. The results are in line with the performance of the LSI.

From the point of view of CNMV, the LSI represents a new tool to analyze and identify potential sources of risks to financial instability. However, this analysis could be improved in the future. In first place, public debt transactions should be included in order to get a whole picture of Spanish bond liquidity; secondly, the analysis will improve when misreporting in TREM is reduced; finally, the results of this paper should be compared and understood in the European context. In this sense, we provide the methodology being discussed in ESMA, that is currently analyzing European bond market liquidity in the period 2012-2016, and show the preliminary results for Spain. We see that the main differences in ESMA's approach (for example, the exclusion of structured bonds and specific indicators related to trading volumes) may lead to a liquidity indicator that worsens over the past years, but less significantly than in our LSI. 


\section{Bibliography}

Amihud, Y. (2002), Illiquidity and stock returns: cross-section and time-series effects, Journal of Financial Markets vol. 5, pp 31-56.

Autorite des marches financiers, (2015), Study of Liquidity in French Bond Markets.

Bonthron, F., Johansson, T. and J. Mannent (2016), Market liquidity on the Swedish bond market and its importance for financial stability, Economic Commentary No. 3, 2016. Sveriges Riskbank.

Broto C. and M. Lamas (2016), Measuring market liquidity in US fixed income markets: A new synthetic indicator, The Spanish Review of Financial Economics vol. 14, pp 15-22.

Cambón M.I. and L. Estévez (2016), A Spanish Financial Markets Stress Index, The Spanish Review of Financial Economics vol. 14, pp 23-41.

ESMA Report on Trends, Risks and Vulnerabilities (2016), EU corporate bond market liquidity, TRV No. 2, September 2016.

ESMA Report on Trends, Risks and Vulnerabilities (2017), EU sovereign bond market liquidity, TRV No. 1, March 2017.

Financial Conduct Authority (2016), Liquidity in UK Corporate Bond Markets: evidence from trade data, Occasional Paper 14.

Hollo, D., Kremer, M. and M. Lo Duca (2012), A composite indicator of systemic stress in the financial system. European Central Bank. Working Paper Series, 1426.

IMF (2015), Global Financial Stability Report, October 2015. International Monetary Fund.

Organization for Economic Co-operation and Development (OECD), 2008, Handbook on constructing composite indicators.

PwC (2015), Global financial markets liquidity study, August 2015.

Sarr, A. and T. Lybek (2002), Measuring liquidity in financial markets. IMF working paper, 02/232. 



\section{Annexes}

\begin{tabular}{|c|c|c|c|c|c|}
\hline \multicolumn{5}{|c|}{ Gross Issues - Financial (million euros) ${ }^{1}$} & \multirow{2}{*}{$\begin{array}{r}\text { TABLE A. } \\
\text { Tota }\end{array}$} \\
\hline & \multicolumn{2}{|c|}{ Registered CNMV (AIAF) } & \multicolumn{2}{|c|}{$\begin{array}{r}\text { Abroad by } \\
\text { Spanish Issuers }{ }^{2}\end{array}$} & \\
\hline \multirow[t]{2}{*}{ Type of asset } & Bonds & Securitisation & Covered & Bonds & \\
\hline & (and debentures) & & \multicolumn{2}{|c|}{ bonds (and debentures) } & \\
\hline \multirow[t]{2}{*}{2005} & $40,059.5$ & $43,486.3$ & 60,220 & $31,804.3$ & $175,570.1$ \\
\hline & $(500.7)$ & (249.9) & $(1,71.2)$ & $(467.7)$ & \\
\hline \multirow[t]{2}{*}{2006} & 45,892 & $65,171.9$ & 74,340 & $35,957.8$ & $221,367.7$ \\
\hline & (424.9) & $(236.1)$ & $(1,143.7)$ & $(230.5)$ & \\
\hline \multirow[t]{2}{*}{2007} & $24,688.9$ & $113,832.2$ & $57,060.5$ & $31,974.1$ & $227,555.7$ \\
\hline & $(338.2)$ & (306.8) & (851.6) & $(236.8)$ & \\
\hline \multirow[t]{2}{*}{2008} & $9,732.8$ & $99,113.9$ & $56,316.6$ & $18,612.7$ & 183,776 \\
\hline & $(131.5)$ & $(316.7)$ & $(662.5)$ & (255) & \\
\hline \multirow[t]{2}{*}{2009} & $60,285.3$ & $64,252.2$ & $44,265.3$ & $17,269.5$ & $186,072.3$ \\
\hline & $(242.1)$ & $(296.1)$ & $(606.4)$ & $(292.7)$ & \\
\hline \multirow[t]{2}{*}{2010} & $23,708.1$ & $45,650.5$ & 57,016 & $26,308.7$ & $152,683.3$ \\
\hline & $(169.3)$ & $(671.3)$ & $(559)$ & $(375.8)$ & \\
\hline \multirow[t]{2}{*}{2011} & $13,943.7$ & $66,060.3$ & $92,245.7$ & $22,574.5$ & $194,824.2$ \\
\hline & $(172.1)$ & $(768.1)$ & $(591.3)$ & $(370.1)$ & \\
\hline \multirow[t]{2}{*}{2012} & $88,794.8$ & $23,547.6$ & 112,844 & $21,743.8$ & $246,930.2$ \\
\hline & $(677.8)$ & $(461.7)$ & $(989.9)$ & (289.9) & \\
\hline \multirow[t]{2}{*}{2013} & $30,108.3$ & $28,752.9$ & $31,714.7$ & $16,668.8$ & $107,244.7$ \\
\hline & (183.6) & $(542.5)$ & (720.8) & $(231.5)$ & \\
\hline \multirow[t]{2}{*}{2014} & $39,078.2$ & 29,028 & $25,691.3$ & 19,640 & $113,437.5$ \\
\hline & $(67.6)$ & (744.3) & (856.4) & (239.5) & \\
\hline \multirow[t]{2}{*}{2015} & 35,432 & $29,071.1$ & 41,775 & 25,110 & $131,388.1$ \\
\hline & (115.8) & (632) & $(1,044.4)$ & (196.2) & \\
\hline \multirow[t]{2}{*}{2016} & 36,283 & $35,270.4$ & $39,142.5$ & $17,515.3$ & $128,310.9$ \\
\hline & (139.4) & $(578.2)$ & (850.9) & (186.3) & \\
\hline
\end{tabular}

Source: AIAF, Bloomberg and CNMV.

1 Data on Spanish issuer's issuance in foreign markets (the country of risk of the issuer is Spain).

2 In brackets, average size issue. 


\begin{tabular}{|c|c|c|c|c|c|}
\hline \multicolumn{5}{|c|}{ Gross Issues - Non-Financial (million euros) } & \multirow{3}{*}{$\begin{array}{r}\text { TABLE A.2 } \\
\text { Total }\end{array}$} \\
\hline & \multicolumn{2}{|c|}{ Registered CNMV (AIAF) } & \multicolumn{2}{|c|}{ Abroad by Spanish Issuers ${ }^{2}$} & \\
\hline $\begin{array}{l}\text { Type } \\
\text { of asset }\end{array}$ & $\begin{array}{r}\text { Bonds } \\
\text { (and debentures) }\end{array}$ & $\begin{array}{l}\text { No. of } \\
\text { issues }\end{array}$ & $\begin{array}{r}\text { Bond (and } \\
\text { debentures) }\end{array}$ & $\begin{array}{l}\text { No. of } \\
\text { issues }\end{array}$ & \\
\hline 2005 & $\begin{array}{l}2,583.6 \\
(369.1)\end{array}$ & 7 & $\begin{array}{l}4,708 \\
(214)\end{array}$ & 22 & $7,291.6$ \\
\hline 2006 & $\begin{array}{l}1,732.3 \\
(288.7)\end{array}$ & 6 & $\begin{array}{r}13,549.7 \\
(483.9)\end{array}$ & 28 & 15,282 \\
\hline 2007 & $\begin{array}{l}1,695.6 \\
(339.1)\end{array}$ & 5 & $\begin{array}{l}5,606.5 \\
(431.3)\end{array}$ & 13 & $7,302.1$ \\
\hline 2008 & $\begin{array}{r}768 \\
(153.6)\end{array}$ & 5 & $\begin{array}{l}5,913.3 \\
(454.9)\end{array}$ & 13 & $6,681.3$ \\
\hline 2009 & $\begin{array}{l}2,231.4 \\
(371.9)\end{array}$ & 6 & $\begin{array}{l}19,696 \\
(447.6)\end{array}$ & 44 & $21,927.4$ \\
\hline 2010 & $\begin{array}{r}600 \\
(200)\end{array}$ & 3 & $\begin{array}{r}11,622.7 \\
(447)\end{array}$ & 26 & $12,222.7$ \\
\hline 2011 & $\begin{array}{r}186.1 \\
(93)\end{array}$ & 2 & $\begin{array}{r}12,186.7 \\
(27)\end{array}$ & 27 & $12,372.8$ \\
\hline 2012 & $\begin{array}{l}2,189.3 \\
(312.8)\end{array}$ & 7 & $\begin{array}{r}14,296.3 \\
(476.5)\end{array}$ & 30 & $16,485.6$ \\
\hline 2013 & $\begin{array}{l}2,675.3 \\
(445.9)\end{array}$ & 6 & $\begin{array}{r}25,337.3 \\
(395.9)\end{array}$ & 64 & $28,012.6$ \\
\hline 2014 & $\begin{array}{l}2,290.4 \\
(163.6)\end{array}$ & 14 & $\begin{array}{r}20,917.7 \\
(426.9)\end{array}$ & 49 & $23,208.1$ \\
\hline 2015 & $\begin{array}{l}3,048.2 \\
(203.2)\end{array}$ & 15 & $\begin{array}{r}16,482.5 \\
(374.6)\end{array}$ & 44 & $19,530.7$ \\
\hline 2016 & $\begin{array}{l}2,523.4 \\
(180.2)\end{array}$ & 14 & $\begin{array}{r}24,709.2 \\
(308.9)\end{array}$ & 80 & $27,232.6$ \\
\hline
\end{tabular}

Source: AIAF, Bloomberg and CNMV.

1 Data on Spanish issuer's issuance in foreign markets (the country of risk of the issuer is Spain).

2 In brackets, average size issue. 


\begin{tabular}{lrrrr}
\multicolumn{1}{c}{ Indicator } & Weight & Indicator & Weight \\
\hline Bid-ask spread government & 0.100 & \% of traded bonds financial & 0.125 \\
\hline Bid-ask spread financial & 0.100 & \% of traded bonds non-financial & 0.025 \\
\hline Bid-ask spread non-financial & 0.050 & Amihud ratio financial & 0.100 \\
\hline Volume financial & 0.125 & Amihud ratio non-financial & 0.025 \\
\hline Volume non-financial & 0.050 & Market efficiency coefficient (MEC) government & 0.050 \\
\hline Turnover financial & 0.125 & Market efficiency coefficient (MEC) financial & 0.050 \\
\hline Turnover non-financial & 0.050 & Market efficiency coefficient (MEC) non-financial & 0.025
\end{tabular}

Source: CNMV.

Individual liquidity indicators weights (sectoral indexes)

\begin{tabular}{lrrr}
\multicolumn{1}{c}{ Financial sector } & & Non-financial sector \\
\hline Indicator & Weight & Indicator & Weight \\
\hline Amihud ratio financial & 0.114 & Amihud ratio non-financial & 0.078 \\
\hline Bid-ask spread financial & 0.209 & Bid-ask spread non-financial & 0.144 \\
\hline $\begin{array}{l}\text { Market efficiency coefficient (MEC) } \\
\text { financial }\end{array}$ & 0.268 & Market efficiency coefficient (MEC) & 0.092 \\
\hline \% of traded bonds financial & & non-financial & \\
\hline $\begin{array}{l}\text { Turnover financial } \\
\text { Volume financial }\end{array}$ & 0.153 & \% of traded bonds non-financial & 0.259 \\
\hline
\end{tabular}

Source: CNMV estimations. 


